\title{
Oxygen Transport Ceramic Membranes
}

\author{
Quarterly Report
}

April 2003 - June 2003

Principal Authors:

Prof. S. Bandopadhyay

Dr. N. Nagabhushana

Issued: August 2003

DOE Award \# DE-FC26-99FT40054

\author{
School of Mineral Engineering, \\ University of Alaska Fairbanks \\ Fairbanks, AK 99775
}

Contributing sub contractors:

1. Prof. Thomas W. Eagar, Dr. Harold R Larson, Mr. Raymundo Arroyave; Massachusetts Institute of Technology, Department of Materials Science and Engineering, Cambridge, Massachusetts 02139

2. Dr. X.-D Zhou, Q. Cai, J. Yang, W. B. Yelon, W. J. James and Prof. H. U. Anderson; Materials Research Center, University of Missouri-Rolla, Rolla, MO 65401

3. Prof. Nigel Browning; Department of Chemical Engineering and Materials Science, University of California-Davis, One Shields Ave, Davis, CA 95616

4. Prof. Alan Jacobson and Prof. C.A. Mims; University of Houston/University of Toronto 


\section{DISCLAIMER}

This report was prepared as an account of work sponsored by an agency of the United States Government. Neither the United States Government nor any agency thereof, nor any of their employees, makes any warranty, express or implied, or assumes any legal liability or responsibility for the accuracy, completeness, or usefulness of any information, apparatus, product, or process disclosed, or represents that its use would not infringe privately owned rights. Reference herein to any specific commercial product, process, or service by trade name, trademark, manufacturer, or otherwise does not necessarily constitute or imply its endorsement, recommendation, or favoring by the United States Government or any agency thereof. The views and opinions of authors expressed herein do not necessarily state or reflect those of the United States Government or any agency thereof 


\begin{abstract}
The present quarterly report describes some of the initial studies on newer compositions and also include newer approaches to address various materials issues such as metal-ceramic sealing.

The report describes the use of oxide-based diffusion barriers to prevent the excessive reaction between perovskite substrate materials and Ni-based liquid alloys from a thermochemical point of view. The description is made thanks to recent developments of kinetic simulation techniques that allow the study of interface formation and phase transformations in reactive metal/ceramic systems. It is expected that techniques similar to the ones described in this report can be used to model and study the interactions between liquid based $\mathrm{Ni}$ alloys and the perovskite substrates themselves. The current quarter's research has also focused on developing a comprehensive reliability model for predicting the structural behavior of the OTMs in realistic conditions. The studies include detailed analysis of secondary phases and impurities/vacancies segregating to grain boundaries in the membrane materials that had previously undergone mechanical testing at the University of Alaska. The initial results indicate the presence of large secondary phases both at the grain boundaries and within the grains. The grain boundary planes themselves, appear to show the same behavior as in previously studied perovskites, i.e. they contain a high level of oxygen vacancies and little (or no) metal segregation. Neutron diffraction and Mössbauer spectroscopy were used to characterize the model perovskite type ferrites, in terms of the crystal structure, oxygen occupancy, magnetic moment, and $\mathrm{Fe}$ valence state. The present quarter studies were on the $\mathrm{Ti}$ doped compositions for which the data were typical of perovskite oxides. The conductivity initially $\mathrm{p}$ type at high oxygen partial pressure decreases as $\mathrm{pO}_{2}$. The slope of the linear region in a log $-\log$ plot is $\sim 1 / 4$ as expected. Little temperature variation is seen in this region presumably because the decrease in hole conductivity associated with oxygen loss is offset by an increase in the ionic conductivity. As the $\mathrm{pO}_{2}$ is further decreased, the conductivity goes through a minimum and then becomes $\mathrm{n}$ type with a $\mathrm{pO}_{2}^{-1 / 4}$ dependence. In general, the system is well behaved with little evidence for problems in attaining equilibrium that we have found in the other iron systems that we have studied.
\end{abstract}


TABLE OF CONTENTS

$\begin{array}{ll}\text { INTRODUCTION } & 1\end{array}$

$\begin{array}{ll}\text { EXECUTIVE SUMMARY } & 4\end{array}$

Task 1. Development of Ceramic Membrane/Metal Joints $\quad 6$

Task 2. Determine material mechanical properties under conditions of $\quad 12$ high temperature and reactive atmosphere

Task 3 . Preparation and Characterization of Dense Ceramic oxygen $\quad 19$

Permeable Membranes

Task 4. Assessment of Microstructure of the Membrane Materials to Evaluate the Effects of vacancy-Impurity Association, defect Clusters, and Vacancy Dopant Association on the Membrane Performance and Stability

Task 5. Measurement of Surface Activation/Reaction rates in Ion Transport Membranes using Isotope Tracer and Transient Kinetic Techniques

REFERENCES 


\section{LIST OF GRAPHICAL MATERIALS}

Figure $1 \quad$ Perovskite/Metal Joint created using TLPB Ni-based alloys

Figure 2 Perovskite/Metal interface. Accompanying table presents compositions indicated by numbers in figure on the left.

Figure 3 Interfacial modification of perovskite substrates.

Figure 4 Zirconia/Ni-TLPB Alloy/Ni-based Super Alloy Interface.

Figure 5 Ti-O Phase Diagram.

Figure 6 Concentration profile of a Ti layer in contact with a zirconia substrate, according to the solution of the Cahn-Hilliard equation.

Figure 7: $\quad$ ASTM standard type A samples of LSF, LSC and LSCF composition to study strength degradation with environment.

Figure 8: $\quad$ Hardness and toughness variation in $\mathrm{La}_{0.2} \mathrm{Sr}_{0.8} \mathrm{Co}_{0.8} \mathrm{Fe}_{0.2} \mathrm{O}_{3-\delta}$

Figure 9: $\quad$ Schematic of stress distribution in a brittle solid with an indentation crack

Figure 10: An indented and cation distribution along a growing crack I the $\mathrm{La}_{0.2} \mathrm{Sr}_{0.8} \mathrm{Fe}_{0.8} \mathrm{Cr}_{0.2} \mathrm{O}_{3-}$ ${ }_{x}$ system : b) close to the indent; c) at half distance from the indent and d) at the crack tip.

Figure 11: $\quad$ An indented flaw exposed to air at $1000^{\circ} \mathrm{C}$ in the $\mathrm{La}_{06} \mathrm{Sr}_{0.4} \mathrm{FeO}_{3-\mathrm{x}}$ system. The crack tip shows healing (in red) upon exposure as also contributing to more damage (in blue)

Figure 12: $\quad$ ASTM standard type B samples of $\mathrm{La}_{0.2} \mathrm{Sr}_{0.8} \mathrm{Fe}_{0.8} \mathrm{Cr}_{0.2} \mathrm{O}_{3-\mathrm{x}}$ composition provided by Praxair to study strength degradation with environment.

Figure 13: (a) Schematic of the STEM. (b) The Z-contrast image and energy loss spectrum can be interpreted as a simple convolution of the experimental probe and the object function. With lower spatial resolution, the EDS spectrum can also be interpreted in this manner.

Figure 14: $\quad$ (a) Bright field (b) Z-contrast and (c) secondary electron images of a representative area of the membrane material.

Figure 15: $\quad$ Elemental profiles of the area shown in figure 2.

Figure 16. $\mathrm{X}$ - ray diffraction data for $\mathrm{La}_{0.2} \mathrm{Sr}_{0.8} \mathrm{Fe}_{0.55} \mathrm{Ti}_{0.45} \mathrm{O}_{3-\mathrm{x}}$ samples annealed at different temperatures. 
Figure 17. Back-scattered electron images of $\mathrm{La}_{0.2} \mathrm{Sr}_{0.8} \mathrm{Fe}_{0.55} \mathrm{Ti}_{0.45} \mathrm{O}_{3-\mathrm{x}}$

Figure 18. DC conductivity data for $\mathrm{La}_{0.2} \mathrm{Sr}_{0.8} \mathrm{Fe}_{0.55} \mathrm{Ti}_{0.45} \mathrm{O}_{3-\mathrm{x}}$ in different gas atmospheres as a function of reciprocal temperature

Figure 19. Conductivity measurements for $\mathrm{La}_{0.2} \mathrm{Sr}_{0.8} \mathrm{Fe}_{0.55} \mathrm{Ti}_{0.45} \mathrm{O}_{3-\mathrm{x}}$ as a function of $\mathrm{pO}_{2}$ at different temperatures. Open and closed symbols represent data taken on increasing and decreasing $\mathrm{pO}_{2}$

Figure 20. The individual contributions to the total conductivity of $\mathrm{La}_{0.2} \mathrm{Sr}_{0.8} \mathrm{Fe}_{0.55} \mathrm{Ti}_{0.45} \mathrm{O}_{3-\mathrm{x}}$.

Figure 21. Oxygen flux as function of $\mathrm{P}_{\mathrm{O} 2}$. He sweep $=20 \mathrm{sccm}$

Figure 22. The effect of sweeping He flow rate on $\mathrm{O}_{2}$ flux for LSCF- 6428 at $800{ }^{\circ} \mathrm{C}$

Figure 23: $\quad$ Isotope transient on the air side of the membrane at $800^{\circ} \mathrm{C}$. The indicated values are of the ratio of the reverse to forward surface exchange coefficients.

Figure 24: $\quad$ Oxygen potential gradient across LSCFO-6428 membrane at $800^{\circ} \mathrm{C}$.

Figure 25: Isotope profile in solid at various times after isotope pulse introduction 
Conversion of natural gas to liquid fuels and chemicals is a major goal for the Nation as it enters the $21^{\text {st }}$ Century. Technically robust and economically viable processes are needed to capture the value of the vast reserves of natural gas on Alaska's North Slope, and wean the Nation from dependence on foreign petroleum sources. Technologies that are emerging to fulfill this need are all based syngas as an intermediate. Syngas (a mixture of hydrogen and carbon monoxide) is a fundamental building block from which chemicals and fuels can be derived. Lower cost syngas translates directly into more cost-competitive fuels and chemicals.

The currently practiced commercial technology for making syngas is either steam methane reforming (SMR) or a two-step process involving cryogenic oxygen separation followed by natural gas partial oxidation (POX). These high-energy, capital-intensive processes do not always produce syngas at a cost that makes its derivatives competitive with current petroleum-based fuels and chemicals.

In the mid 80's BP invented a radically new technology concept that will have a major economic and energy efficiency impact on the conversion of natural gas to liquid fuels, hydrogen, and chemicals. ${ }^{1}$ This technology, called Electropox, integrates oxygen separation with the oxidation and steam reforming of natural gas into a single process to produce syngas with an economic advantage of 30 to 50 percent over conventional technologies. ${ }^{2}$

The Electropox process uses novel and proprietary solid metal oxide ceramic oxygen transport membranes [OTMs], which selectively conduct both oxide ions and electrons through their lattice structure at elevated temperatures. ${ }^{3}$ Under the influence of an oxygen partial pressure gradient, oxygen ions move through the dense, nonporous membrane lattice at high rates with 100 percent

\footnotetext{
${ }^{1}$ Mazanec, T. J.; Cable, T. L.; Frye, J. G., Jr.; US 4,793,904, 27 Dec 1988, assigned to The Standard Oil Company (now BP America), Mazanec, T. J.; Cable, T. L.; US 4,802,958, 7 Feb 1989, assigned to the Standard Oil Co. (now BP America), Cable, T. L.; Mazanec, T. J.; Frye, J. G., Jr.; European Patent Application 0399833, 24 May 1990, published 28 November 1990.

${ }^{2}$ Bredesen, R.; Sogge, J.; "A Technical and Economic Assessment of Membrane Reactors for Hydrogen and Syngas Production" presented at Seminar on the Ecol. Applic. of Innovative Membrane Technology in the Chemical Industry", Cetraro, Calabria, Italy, 1-4 May 1996.

${ }^{3}$ Mazanec, T.J., Interface, 1996; Mazanec, T.J., Solid State Ionics, 70/71, 1994 11-19; "Electropox: BP's Novel Oxidation Technology", T.J. Mazanec, pp 212-225, in "The Role of Oxygen in Improving Chemical Processes", M. Fetizon and W.J. Thomas, eds, Royal Society of Chemistry, London, 1993; "Electropox: BP's Novel Oxidation Technology", T.J. Mazanec, pp 85-96, in "The Activation of Dioxygen and Homogeneous Catalytic Oxidation", D.H.R. Barton, A. E. Martell, D.T. Sawyer, eds, Plenum Press, New York, 1993; "Electrocatalytic Cells for Chemical Reaction", T.J. Mazanec, T.L. Cable, J.G. Frye, Jr.; Prep Petrol Div ACS, San Fran, 1992 37, 135-146; T.J. Mazanec, T.L. Cable, J.G. Frye, Jr.; Solid State Ionics, 1992, 53-56, 111-118.
} 
selectivity. Transported oxygen reacts with natural gas on the fuel side of the ceramic membrane in the presence of a catalyst to produce syngas.

In 1997 BP entered into an OTM Alliance with Praxair, Amoco, Statoil and Sasol to advance the Electropox technology in an industrially sponsored development program. These five companies have been joined by Phillips Petroleum and now are carrying out a multi-year $\$ 40+$ million program to develop and commercialize the technology. The program targets materials, manufacturing and engineering development issues and culminates in the operation of semi-works and demonstration scale prototype units.

The Electropox process represents a truly revolutionary technology for conversion of natural gas to synthesis gas not only because it combines the three separate unit operations of oxygen separation, methane oxidation and methane steam reforming into a single step, but also because it employs a chemically active ceramic material in a fundamentally new way. On numerous fronts the commercialization of Electropox demands solutions to problems that have never before been accomplished. Basic problems in materials and catalysts, membrane fabrication, model development, and reactor engineering all need solutions to achieve commercial success.

Six important issues have been selected as needing understanding on a fundamental level at which the applied Alliance program cannot achieve the breadth and depth of understanding needed for rapid advancement. These issues include:

1. Oxygen diffusion kinetics (University of Houston);

2. Grain structure and atomic segregation (University of Illinois - Chicago);

3. Phase stability and stress development (University of Missouri - Rolla);

4. Mechanical property evaluation in thermal and chemical stress fields (University of Alaska Fairbanks); and,

5. Graded ceramic/metal seals (Massachusetts Institute of Technology).

\section{Statement of Work}

Task 1 Design, fabricate and evaluate ceramic to metal seals based on graded ceramic powder / metal braze joints.

Task 2 Determine materials mechanical properties under conditions of high temperatures and reactive atmospheres.

Task 3 Evaluate phase stability and thermal expansion of candidate perovskite membranes and develop techniques to support these materials on porous metal structures. 
Task 4 Assess the microstructure of membrane materials to evaluate the effects of vacancyimpurity association, defect clusters, and vacancy-dopant association on the membrane performance and stability.

Task 5 Measure kinetics of oxygen uptake and transport in ceramic membrane materials under commercially relevant conditions using isotope labeling techniques. 


\section{EXECUTIVE SUMMARY}

Research on the Oxygen Transport Membranes as listed as tasks 1-5 are being performed at the various universities under the stewardship of Praxair. The technical report presents the progress of the various tasks defined to understand the fundamental concepts and the performance of the ceramic membrane in realistic conditions.

Throughout the development of this project, it has been found that, contrary to what is the case in the majority of the ceramic/metal applications encountered in industry, perovskite substrates are easily wetted, even by relatively inactive liquid alloys. This is of great importance, since this allows, at least in principle, the use of liquid-based joining techniques for the creation of ceramic/metal seals that are necessary for the proper functioning of the Gas-to-Liquid reactor system. Since zirconia-based ceramics are compatible with perovskite materials and have a rather large thermochemical stability, the possibility of using thin films of these ceramics as diffusion barriers was explored in subsequent stages of the project. Experimentally, it was found that zirconia substrates could be joined to Ni-based alloys through the use of Ni-based TLPB melts, provided that the zirconia substrate was modified through the deposition of thin active metals, such as Ti. In order to understand the thermochemical interactions occurring at the zirconia/Ti interface, a model based on the kinetics described by the Cahn-Hilliard equation was developed. It as found that this model describe, to a great degree of accuracy, the reaction sequence that is expected to happen as $\mathrm{Ti}$ is put in contact with zirconia. Given the proper thermodynamic data, it may be possible to describe the nature of the interactions between the perovskite-based ceramics and the Ni-based liquids using similar models to the one described in this report. Eventually, the models will allow the better design of the joining procedure necessary to create a reliable perovskite/metal seal.

The complexities in the structural property characterization $\mathrm{La}_{0.2} \mathrm{Sr}_{0.8} \mathrm{Fe}_{0.8} \mathrm{Cr}_{0.2} \mathrm{O}_{3-\mathrm{x}}$ membranes have been an increased focus of study. Earlier studies on C-rings encountered problems in non-uniform stress distribution and cation migration. To address these issues, studies were initiated on well studied and model compositions. Developing a comprehensive model incorporating initiation and growth of flaws and their relation to degradation process has been the focus in addressing reliability issues in the membrane. The work is complemented by the research being performed at UC Davis (following on from the initial work at UIC) using the advanced atomic resolution techniques in scanning transmission electron microscopy (STEM) to investigate the structure, composition and bonding changes that occur within grains, at grain boundaries, at domain boundaries and within ordered structures in the ceramic membrane materials. Previous years work, provided information on vacancy ordering within the grains of the ceramic membranes. The current quarter's research has focused on the analysis of secondary phases and impurities/vacancies segregating to grain boundaries in the membrane materials that had previously undergone mechanical testing at the University of Alaska. The initial results indicate the presence of large secondary phases both at the grain boundaries and within the grains. The grain boundary planes themselves, appear to show the same behavior as in previously studied perovskites, i.e. they contain a high level of oxygen vacancies and little (or no) metal segregation.

Neutron diffraction and Mössbauer spectroscopy were used to characterize the perovskite type ferrites, in terms of the crystal structure, oxygen occupancy, magnetic moment, and Fe valence state. It was found that a lower symmetry trigonal space group P-3C1 gives improved fits to the data including the matching of a peak not fitted in the $\mathrm{R} \overline{3} \mathrm{c}$ symmetry. A significant lattice distortion from rhombohedral to cubic was observed in $\mathrm{La}_{0.60} \mathrm{Sr}_{0.40} \mathrm{FeO}_{3-\delta}$ quenched from $1200^{\circ} \mathrm{C}$, the average Fe valence states are $\sim 3.04$ and 3.36 for $\mathrm{La}_{0.60} \mathrm{Sr}_{0.40} \mathrm{FeO}_{3-\delta}$ quenched from $1500^{\circ} \mathrm{C}$ and $700^{\circ} \mathrm{C}$ respectively. Results from neutron diffraction and Mössbauer spectroscopy indicated that (1) in the specimen without quenching, there was not significant oxygen vacancy, $(\delta=0)$ and ratio of $\mathrm{Fe}^{3+}$ over 
$\mathrm{Fe}^{4+}$ is $6 / 4$; and (2) in the sample quenched from $1500^{\circ} \mathrm{C}, \delta$ was $\sim 0.2$ and $\mathrm{Fe}$ exhibited a valence state $\sim 3+$.

The present quarter studies were on the Ti doped compositions for which the data were typical of perovskite oxides. The conductivity initially $\mathrm{p}$ type at high oxygen partial pressure decreases as $\mathrm{pO}_{2}$. The slope of the linear region in a log $-\log$ plot is $\sim 1 / 4$ as expected. Little temperature variation is seen in this region presumably because the decrease in hole conductivity associated with oxygen loss is offset by an increase in the ionic conductivity. As the $\mathrm{pO}_{2}$ is further decreased, the conductivity goes through a minimum and then becomes $\mathrm{n}$ type with a $\mathrm{pO}_{2}^{-1 / 4}$ dependence. In general, the system is well behaved with little evidence for problems in attaining equilibrium that we have found in the other iron systems that we have studied. The $\mathrm{p}$ to $\mathrm{n}$ transition is well defined at all temperatures. The studies of the $\mathrm{La}_{0.2} \mathrm{Sr}_{0.8} \mathrm{Fe}_{0.55} \mathrm{Ti}_{0.45} \mathrm{O}_{3-\mathrm{x}}$ sample will be extended to include measurements of the oxygen partial pressure dependence of the oxygen stoichiometry and electrical conductivity relaxation studies to determine the diffusion and the surface exchange coefficients. The flux dependence on oxygen partial pressure both the air side and on the deliver side were seen to be in fair agreement with the previous membrane. Also Isotope transients were performed at $750^{\circ} \mathrm{C}$, $800^{\circ} \mathrm{C}$ and $850^{\circ} \mathrm{C}$. and measurements extended to simultaneously record the transient on the air side. The oxygen activity profile through the membrane was calculated from the obtained surface and bulk kinetics. Isotope transients were performed at different oxygen pressure gradients, by varying the He sweep rate and the oxygen pressure on the air side and the membrane quenched during the final isotope transient were sectioned for isotope profiling 


\section{Task 1 Development of Ceramic Membrane/Metal Joints \\ Prof. Thomas W. Eagar, Dr Harold R Larson, Mr Raymundo Arroyave and Ms Jocelyn L. Wiese}

\section{EXPERIMENTAL}

\section{Perovskite-Braze Interactions}

Contrary to most ceramic/metal liquid-phase joining applications, perovskites based on the $\mathrm{LaMO}_{3}$ were shown to be wetted by conventional Ni-based TLPB alloys. Such alloys were used because of their relatively high oxidation resistance and melting temperature, which would make them suitable for the creation of reliable seals in this particular application. Figure 6 shows an example of a perovskite/metal joint created with such kinds of alloys. As can be seen in the figure, although a successful joint was created, a circumferential crack was nucleated after just a few thermal cycles. The appearance of such cracks is clearly detrimental to the integrity of the seal. Crack nucleation at these ceramic/metal interfaces was related to the excessive reaction between the perovskite substrate and the liquid Ni-based metal:

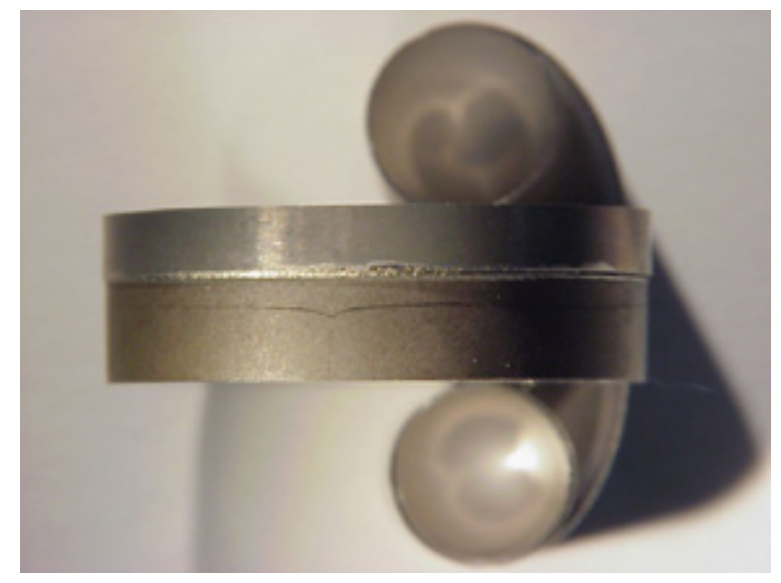

Figure 6 Perovskite/Metal Joint created using TLPB Ni-based alloys

Figure 7 depicts a classic perovskite/metal interface obtained through the use of a Ni-based TLPB alloy. As can be seen in the figure, the diffusional reactions occurring at the interface are very intensive (points 4,6 and 6 indicating reactions products) and from the layering of the interface it is evident that even relatively non-reactive alloys such as the ones used in this work extensive localized 
reduction takes place ${ }^{4}$. Although a limited degree of chemical interaction between ceramic substrate and liquid alloy is desired in most ceramic/metal applications, interfacial reactions as extensive as the ones depicted in Figure 7 result in loss of substrate integrity and in fact it has been proven that microcracks tend to nucleate at the region corresponding to decomposed perovskite. Since this excessive reaction is unacceptable, it is obvious that the perovskite/metal interface must be modified.

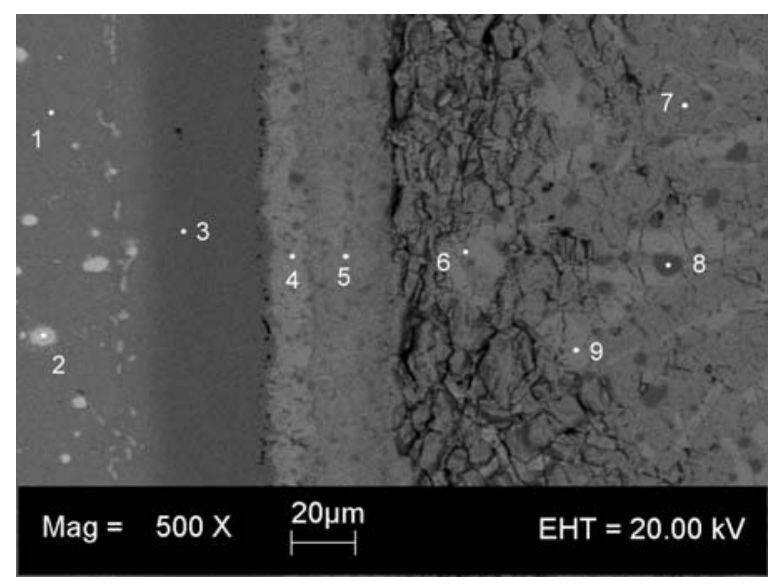

\begin{tabular}{|c|c|c|c|c|c|c|c|c|}
\hline & 1 & 2 & 3 & 4 & 5 & 6,9 & 7 & 8 \\
\hline $\mathrm{Ni}$ & 56 & 21 & 70 & 0 & 0 & 0 & 0 & 0 \\
\hline $\mathrm{Cr}$ & 25 & 30 & 9 & 0 & 0 & 0 & 0 & 0 \\
\hline $\mathrm{W}$ & 13 & 40 & 0 & 0 & 0 & 0 & 0 & 0 \\
\hline $\mathrm{Mo}$ & 1 & 0 & 0 & 0 & 0 & 0 & 0 & 0 \\
\hline $\mathrm{Ti}$ & 0 & 0 & 0 & 0 & 0 & 0 & 0 & 0 \\
\hline $\mathrm{Si}$ & 0 & 0 & 3 & 0 & 0 & 0 & 0 & 0 \\
\hline $\mathrm{Fe}$ & 2 & 1 & 7 & 1 & 1 & 14 & 15 & 69 \\
\hline $\mathrm{La}$ & 0 & 0 & 0 & 23 & 12 & 13 & 15 & 1 \\
\hline $\mathrm{Sr}$ & 0 & 0 & $8 ?$ & 1 & 15 & 8 & 8 & 2 \\
\hline $\mathrm{O}$ & 0 & 0 & 0 & 76 & 71 & 65 & 62 & 29 \\
\hline $\mathrm{Mn}$ & 4 & 4 & 0 & 0 & 0 & 0 & 0 & 0 \\
\hline
\end{tabular}

Figure 7 Perovskite/Metal interface. Accompanying table presents compositions indicated by numbers in figure on the left.

\section{Zirconia Ceramics as Diffusion Barriers}

In this project several approaches have been investigated in order to develop an effective way of prevent the excessive interfacial interactions occurring when attempting to create perovskite/metal seals using liquid alloys. Many of these approaches were based on the creation of a diffusion barrier directly on top of the perovskite substrate. In order to do this, physical vapor deposition techniques were used to deposit thin films of metals that could be easily oxidized and form a protective barrier that would limit the reduction of the perovskite substrate. Although the thin films could be easily deposited on the substrate, it was found that the TLPB alloy was able to penetrate through the film and attack the perovskite substrate.

Given the limitations of the diffusion barriers that were investigated in earlier stages of the project, it was decided that it was necessary to explore other alternative barriers that were more stable and thus capable of protecting the perovskite membrane in a better way. Given their thermodynamic stability

\footnotetext{
${ }^{4}$ The lanthanum and strontium oxides precipitating out of the perovskite substrate indicate localized reduction of the membrane.
} 
and their relatively large coefficient of thermal expansion (compared to that of other oxides such as alumina), zirconia-based ceramics were considered as a possible solution to the problem in question.

Figure 8 shows the basic idea behind the use of a zirconia thin layer that would serve as a protective coating for the perovskite substrate. Since zirconia is one of the most stable ceramic oxides, conventional Ni-based alloys would not be able to wet it. In order to promote wetting, it was found that the zirconia layer needed to be modified. To this effect, a relatively thin layer $(5 \mu \mathrm{m})$ of Ti was deposited, through sputtering on the zirconia surface. Due to the strong thermochemical interaction between $\mathrm{Ti}$ and $\mathrm{Ni}$ and $\mathrm{Ti}$ and $\mathrm{ZrO}_{2}$, it was expected that the addition of this layer would promote adhesion between the Ni-based alloy and the zirconia substrate.

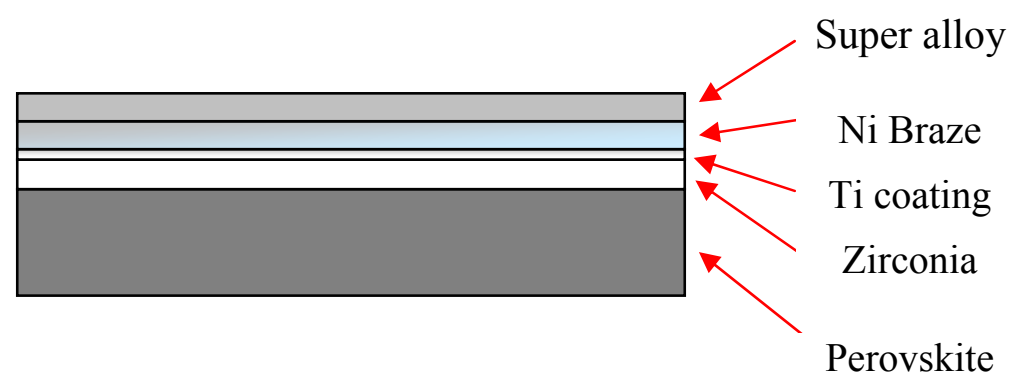

Figure 8 Interfacial modification of perovskite substrates.

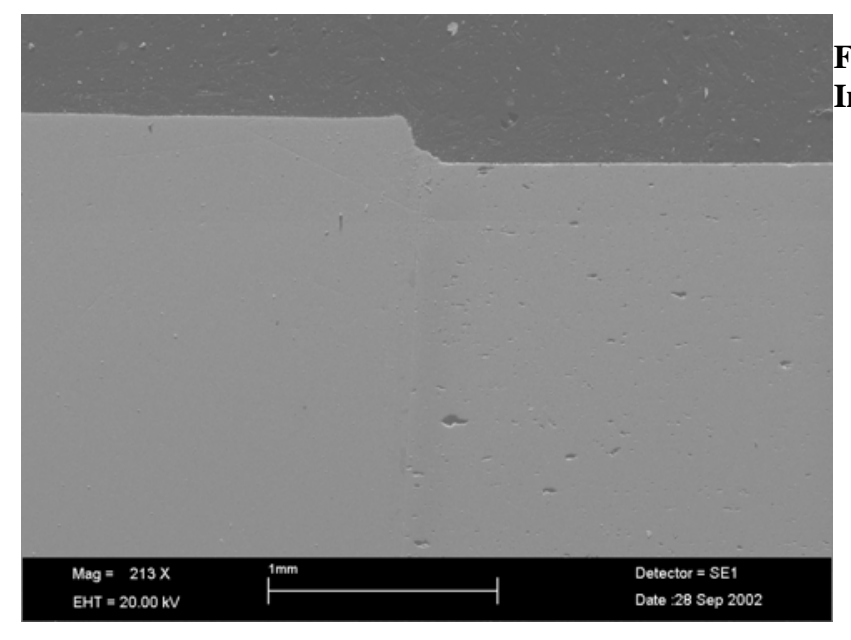

Figure 9 Zirconia/Ni-TLPB Alloy/Ni-based Super Alloy Interface.

Figure 9 shows that, by using Ti coatings over zirconia substrates it is possible to obtain full adhesion between the Ni-based TLPB alloy and the zirconia substrate. In order to understand the zirconia/Ti interfaces formation process, it was decided to develop a model that would describe the thermodynamic and kinetic aspects of the zirconia/Ti interactions. 


\section{RESULTS AND DISCUSSION}

\section{Modeling of Zirconia/Ti Interactions}

As zirconia reacts with $\mathrm{Ti}$, oxygen vacancies are created according to the reaction:

$$
2 Z r_{Z r}^{X}+O_{O}^{X} \Rightarrow 2 \cdot Z r_{Z r}^{\prime}+V_{O}^{\bullet \bullet}+\frac{1}{2} O_{2}(g)
$$

Because of the high chemical affinity between $\mathrm{O}$ and $\mathrm{Ti}$, a large oxygen chemical potential gradient is created across the $\mathrm{C} / \mathrm{M}$ interface as soon as the ceramic oxide is put in contact with Ti. This gradient constitutes the driving force necessary to carry out $(0.1)$. As oxygen vacancies are created according to (0.1), oxygen atoms diffuse towards the zirconia/Ti interface. As zirconia reacts with $\mathrm{Ti}$, a sequence of titanium oxides is formed at the interface and the complex layering grows with time until chemical equilibrium is reached.

According to experimental results the titanium reaction layer often found at zirconia/Ti interfaces is $\mathrm{TiO}_{1-\mathrm{x}}$. The nature of the first-forming titanium-oxygen compound at the $C / M$ interface is determined by the interfacial oxygen chemical potential, which can be fixed by additional chemical reactions occurring in the system.

In general, for zirconia/Ti interfacial reactions involving active metal brazing ${ }^{5}$, it can be assumed that:

- As soon as the Ti thin film over the zirconia interface is put in contact with the zirconia substrate oxygen vacancies will be formed in the latter. The freed oxygen ions will diffuse towards the $\mathrm{Ti}$ film, due to the large oxygen chemical potential gradient across the zirconia/Ti interface.

- As oxygen diffuses out of the zirconia lattice, unsaturated bcc-Ti(O) forms. As oxygen continues to flow across the zirconia/Ti interface a second phase, hcp-Ti(O) precipitates and becomes increasingly saturated with oxygen until it reaches the saturation composition $\mathrm{Ti}_{2} \mathrm{O}$. If the oxygen chemical potential at the interface is fixed at a suitable value, the $\mathrm{TiO}_{1-\mathrm{x}}$ phase

\footnotetext{
${ }^{5}$ It is possible to make similar assertions with regard to other zirconia/Ti interaction systems, such as those described by Arroyave.
} 
may precipitate (See Figure 10, horizontal arrow), provided there are no kinetic barriers for its nucleation and growth.

- When cooling the sample, solid-state transformations can take place, transforming the reaction layer to oxide phases stable at low temperatures.

It has been shown that it is possible to model the Ti/zirconia thermochemical interactions through the solution of the so-called Cahn-Hilliard equation,

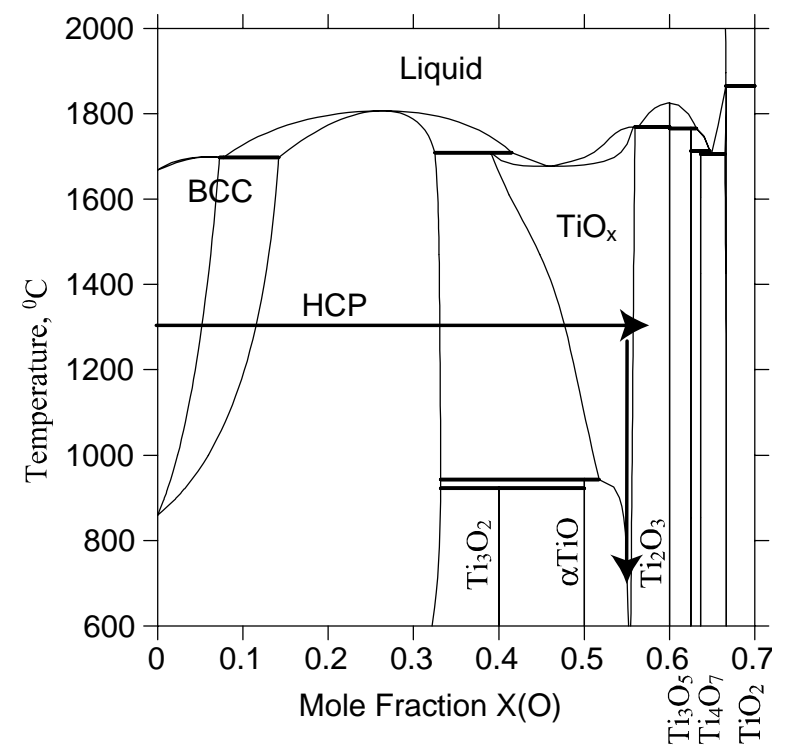

Figure 10 Ti-O Phase Diagram.

$$
\begin{aligned}
\frac{d c}{d t} & =-\nabla \cdot M \cdot \nabla\left(\frac{\partial f}{\partial c}-2 k \nabla^{2} c(x)\right) \\
& =M\left(\nabla^{2}\left(\frac{\partial f}{\partial c}\right)-2 k \nabla^{4} c(x)\right)
\end{aligned}
$$

Where $c$ is the composition, $M$ is the atomic mobility, and $\frac{\partial f}{\partial c}$ corresponds to the oxygen chemical potential at any region of the system. 
Through the numerical solution of (0.2), it has been possible to describe the evolution of zirconia/Ti interactions. In Figure 11 some of the results are shown. As can be seen, the reaction sequence through which bcc-Ti is transformed into a Ti-oxide, as was observed in the experiments corresponding to Figure 9, is correctly represented through the solution of the Cahn-Hilliard Equation.
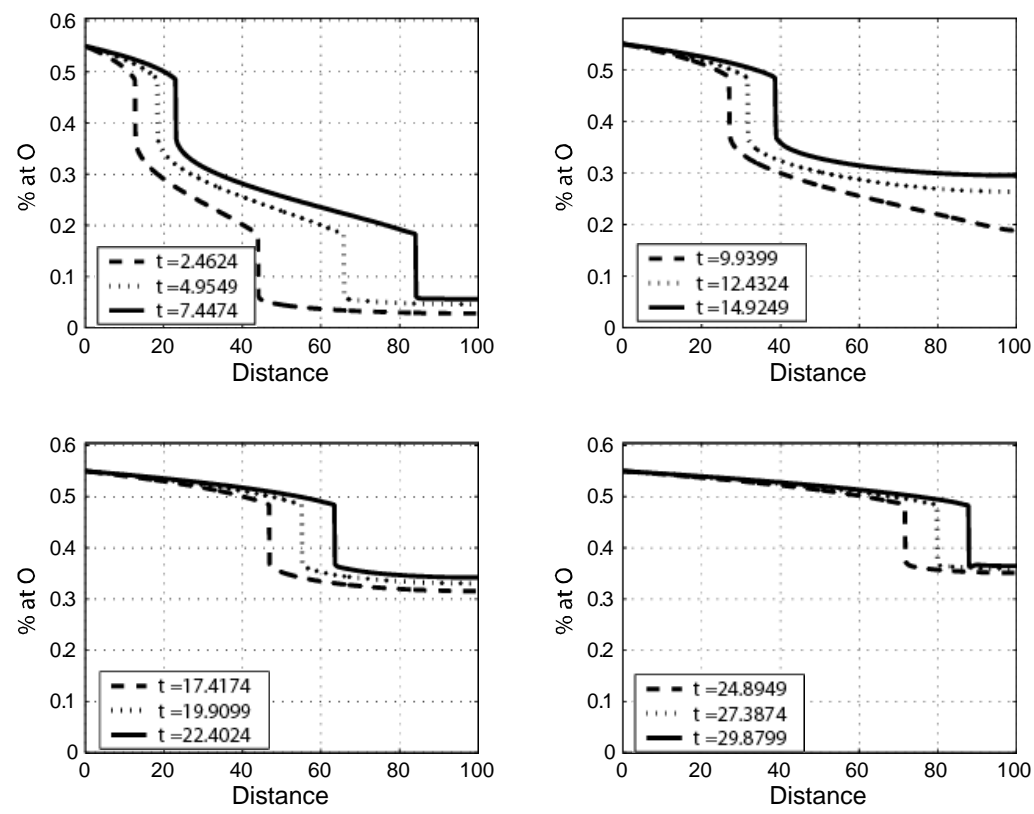

Figure 11 Concentration profile of a Ti layer in contact with a zirconia substrate, according to the solution of the Cahn-Hilliard equation.

\section{CONCLUSIONS}

A better model for the thermochemical interactions between zirconia layers and Ti thin films allows a better estimation of the processing times necessary to obtain a stable interface in perovskite/metal applications where zirconia-based diffusion barriers are used to decrease the interaction between the TLPB alloy and the substrate itself. Furthermore, the model develop in this work may eventually be applied to describe the detrimental liquid metal/perovskite interactions that prevent the creation of reliable perovskite/metal interfaces without the use of protective diffusion barriers. 


\title{
TASK 2: Determine material mechanical properties under conditions of high temperature and reactive atmosphere
}

\author{
Prof. Sukumar Bandopadhyay and Dr. Nagendra Nagabhushana \\ University of Alaska Fairbanks
}

\section{EXPERIMENTAL PROCEDURE}

Beams of composition as mentioned in the previous report were fabricated (fig. 7). The sample were characterized by XRD, optical microscopy and density measurements. The toughness of the materials were measured by indentation technique at various loads. The indents were observed in a Scanning Electron microscope and the elemental variation around the crack tip and the indent were characterized by electron dispersive spectroscopy. The indent were exposed to air at $1000^{\circ} \mathrm{C}$ to characterize for possible stress-aided cation migration and decomposition. Post exposure sample were also indented to measure for degradation in toughness values.

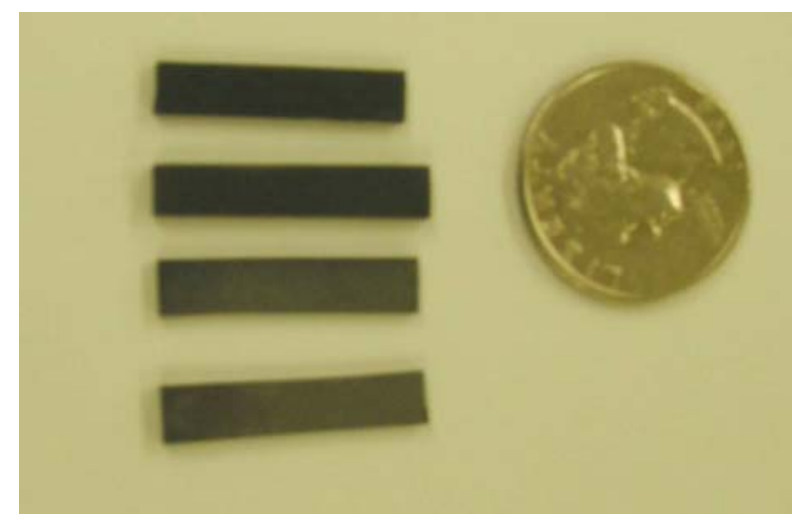

Figure 7: $\quad$ ASTM standard type A samples of LSF, LSC and LSCF composition to study strength degradation with environment.

\section{RESULTS AND DISCUSSIONS:}

The results of the indentation hardness and toughness studies on Lanthanum based compositions are tabulated in table 1. As noted earlier, the B site is varied from fully Co to fully Fe cation occupation. The $\mathrm{Co} / \mathrm{Fe}$ ratio on the $\mathrm{B}$ site and the $\mathrm{La} / \mathrm{Sr}$ ratio on the $\mathrm{A}$ site are also varied. The hardness and toughness were measured as a function of indentation load and corresponded to measured values available in literature. As shown in the table 2, no perceptible change was observed with the indentation load. However, lateral cracks were well defied at higher loads. The higher loads also showed incidences of damage accumulation in the materials. 
A graphical representation of the variation in hardness and toughness is shown in figure 8 . The results are for the compositions $\mathrm{La}_{\mathbf{0 . 2}} \mathrm{Sr}_{\mathbf{0 . 8}} \mathrm{Co}_{\mathbf{0 . 8}} \mathrm{Fe}_{0.2} \mathrm{O}_{3-\delta}$

Table 2: Indentation hardness and toughness values for the composition being evaluated.

\begin{tabular}{|c|c|c|c|}
\hline Material & Load (gms) & $\begin{array}{l}\text { Hardness, GPa } \\
\text { (STD Dev) }\end{array}$ & $\begin{array}{l}\text { Fracture Toughness, MPa.m } \\
\text { (STD Dev) }\end{array}$ \\
\hline & 50 & $8.73( \pm 0.92)$ & $1.03( \pm 0.23)$ \\
$\mathbf{L a}_{\mathbf{0 . 8}} \mathbf{S r}_{\mathbf{0 . 2}} \mathbf{C o O}_{3-\delta}$ & 100 & $8.93( \pm 0.40)$ & $1.28( \pm 0.42)$ \\
& 200 & $8.25( \pm 0.60)$ & $1.10( \pm 0.18)$ \\
& 300 & $8.27( \pm 0.56)$ & $1.16( \pm 0.17)$ \\
& 500 & $7.56( \pm 0.53)$ & $1.07( \pm 0.23)$ \\
& 1000 & $7.07( \pm 0.47)$ & $1.17( \pm 0.13)$ \\
& 50 & $8.19( \pm 1.86)$ & $1.59( \pm 0.72)$ \\
& 100 & $7.42( \pm 0.60)$ & $1.46( \pm 0.30)$ \\
$\mathbf{L a}_{\mathbf{0 . 6}} \mathbf{S r}_{\mathbf{0 . 4}} \mathbf{C o}_{\mathbf{0 . 2}} \mathbf{F e}_{\mathbf{0 . 8}} \mathbf{O}_{3-\delta}$ & 200 & $7.44( \pm 0.95)$ & $1.38( \pm 0.44)$ \\
& 300 & $7.44( \pm 0.36)$ & $1.10( \pm 0.52)$ \\
& 500 & $6.48( \pm 0.99)$ & $1.10( \pm 0.31)$ \\
& 1000 & $6.56( \pm 0.58)$ & $0.91( \pm 0.14)$ \\
\hline & 50 & $7.77( \pm 1.27)$ & $2.25( \pm 0.27)$ \\
& 100 & $9.15( \pm 0.69)$ & $2.56( \pm 0.31)$ \\
$\mathbf{L a}_{\mathbf{0 . 8}} \mathbf{S r}_{\mathbf{0 . 2}} \mathbf{C o}_{\mathbf{0 . 8}} \mathbf{F e}_{\mathbf{0 . 2}} \mathbf{O}_{\mathbf{3}-\delta}$ & 200 & $8.41( \pm 1.011)$ & $2.48( \pm 0.23)$ \\
& 300 & $8.7( \pm 0.91)$ & $2.43( \pm 0.5)$ \\
& 500 & $7.79( \pm 0.57)$ & $2.25( \pm 0.57)$ \\
& 1000 & $6.61( \pm 0.45)$ & $1.71( \pm 0.47)$ \\
\hline $\mathbf{L a}_{\mathbf{0 . 6}} \mathbf{S r}_{\mathbf{0 . 4}} \mathbf{F e O}_{3-\delta}$ & 50 & $10.50( \pm 1.06)$ & $1.73( \pm 0.44)$ \\
& 100 & $9.52( \pm 0.56)$ & $1.98( \pm 0.60)$ \\
& 200 & $9.02( \pm 0.29)$ & $1.27( \pm 0.39)$ \\
& 300 & $9.05( \pm 0.24)$ & $1.70( \pm 0.45)$ \\
& 500 & $8.80( \pm 0.80)$ & $1.57( \pm 0.58)$ \\
& 1000 & $7.82( \pm 0.43)$ & $1.05( \pm 0.16)$ \\
\hline & &
\end{tabular}




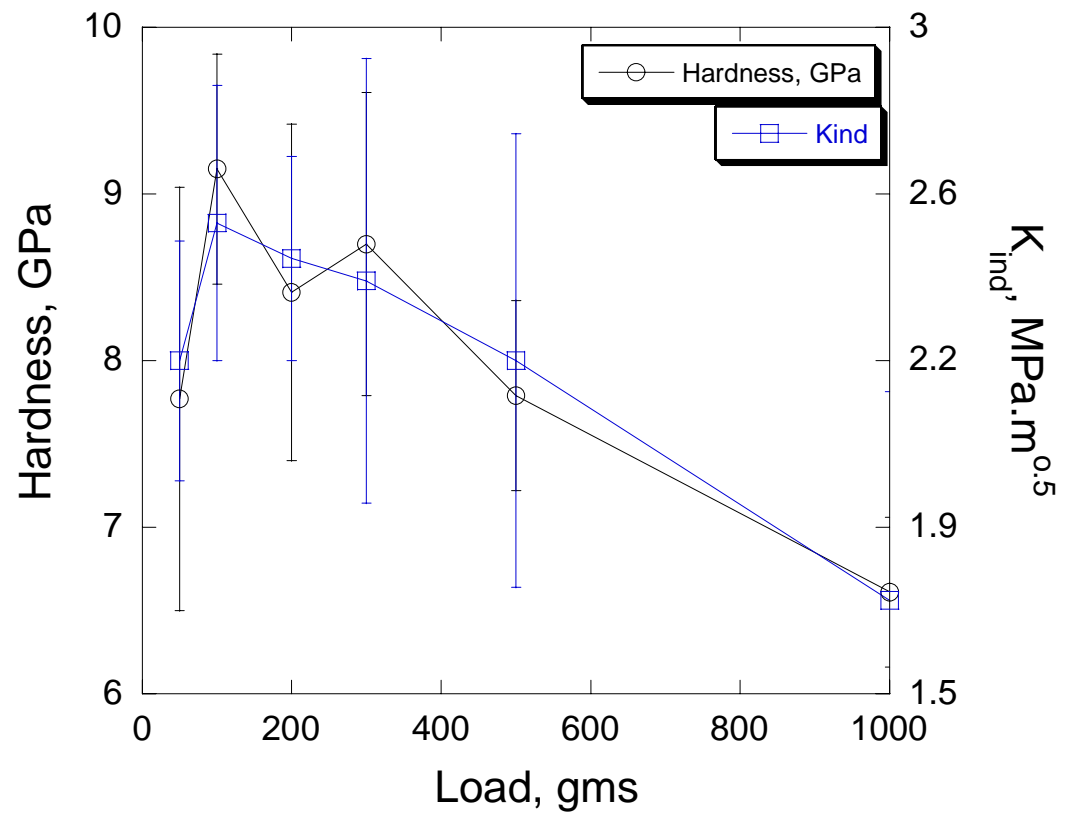

Figure 8: $\quad$ Hardness and toughness variation in $\mathbf{L a}_{\mathbf{0 . 2}} \mathbf{S r}_{\mathbf{0 . 8}} \mathbf{C o}_{\mathbf{0 . 8}} \mathbf{F e}_{\mathbf{0 . 2}} \mathbf{O}_{3-\delta}$

\section{Development Of Reliability Model for OTM's}

In developing a reliability model for the OTM it is necessary to know the behavior of the material in response to its operating environment. As part of our earlier studies on $\mathrm{La}_{0.2} \mathrm{Sr}_{0.8} \mathrm{Fe}_{0.8} \mathrm{Cr}_{0.2} \mathrm{O}_{3-\mathrm{x}}$ membranes and dissemination to the scientific community, it has been shown that various issues need to be resolved in developing a comprehensive reliability model for these class of materials. Specifically, the questions that need to be addressed are:

* Flaws, fracture initiation and crack propagation

Is failure flaw-initiation controlled or propagation controlled?

How does a crack/flaw initiate?

How does a crack/flaw interact with the microstructure?

- Sequence and specific influence of transitions and decomposition (if any?) on the fracture processes

State of stresses evolved upon decomposition of the membranes and their influence on crack growth

* Phase changes, thermal expansion (lattice and chemical expansion)

Are they reversible? 
Quantification of the effect of environment on membranes structural properties

* Slow Crack growth

Creep

Life time estimation

- Cohesive Weibull models with fracture processes and mechanisms

To understand the behavior of flaws, their initiation and propagation initial studies were done with flaws generated by Vickers indent. As shown in figure 9, the stress distribution in a Vickers indent in a brittle material can be well defined. We will try to correlate the stress distribution in a well characterized Vickers indent flaw, with effects coming from stresses generated by cation movement, degradation of the material etc.

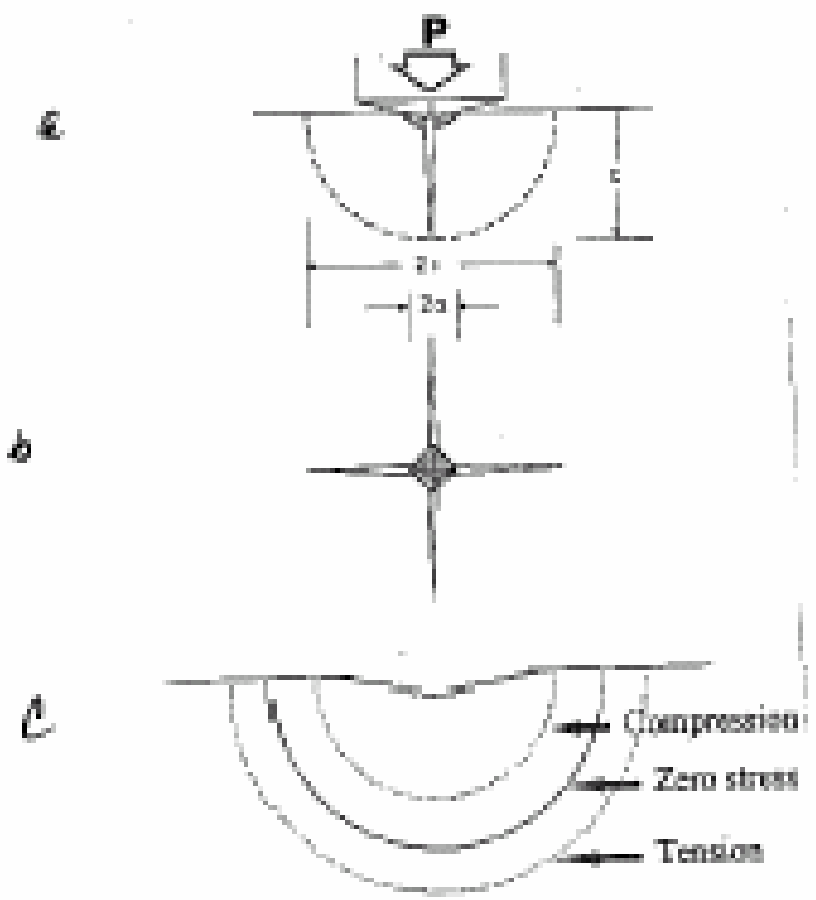

Schematic of Indentation Crack Fomation: a) Cross Section Through Indent Zone Showing Radial Crack Limits (dashed line), b) Intersection of Radial Cracks with Surface of Sheet, c) Dependence of Crack Size on Local Stresses

Figure 9: $\quad$ Schematic of stress distribution in a brittle solid with an indentation crack 


\section{$\underline{\text { Indentation flaw characterization in } L a_{0.2}} \underline{S}_{0.8} \underline{F_{0.8}} \underline{\operatorname{Cr}_{0.2}} \underline{\underline{O}}_{3-x}$}

The cation distribution in the stress field around an indented flaw was analyzed in $\mathrm{La}_{0.2} \mathrm{Sr}_{0.8} \mathrm{Fe}_{0.8} \mathrm{Cr}_{0.2} \mathrm{O}_{3-\mathrm{x}}$ composition (figure 9).
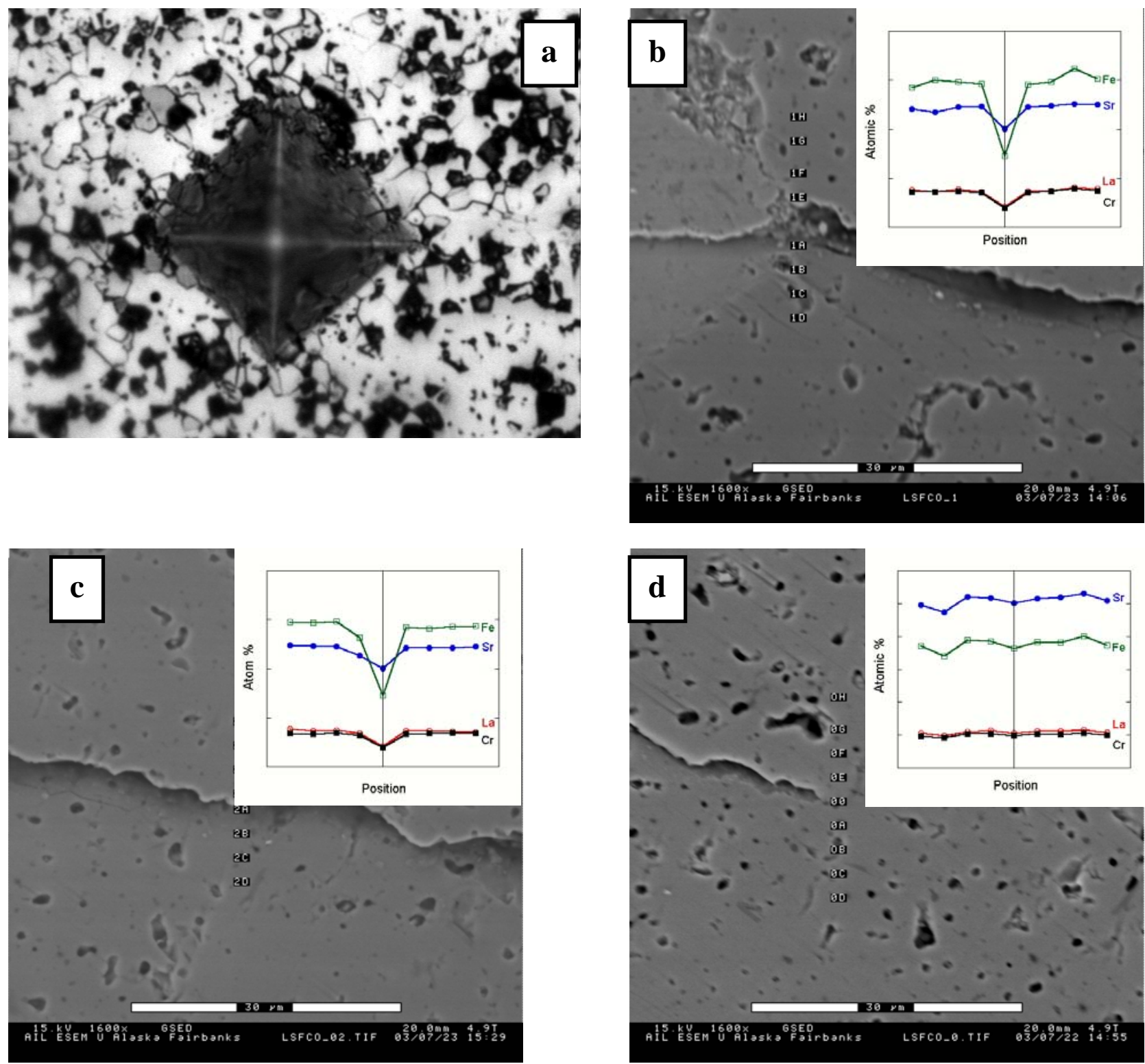

Figure 10: An indented and cation distribution along a growing crack I the $\mathrm{La}_{0.2} \mathrm{Sr}_{0.8} \mathrm{Fe}_{0.8} \mathrm{Cr}_{0.2} \mathrm{O}_{3-\mathrm{x}}$ system : b) close to the indent; c) at half distance from the indent and d) at the crack tip.

Initial studies done on the $\mathrm{La}_{0.2} \mathrm{Sr}_{0.8} \mathrm{Fe}_{0.8} \mathrm{Cr}_{0.2} \mathrm{O}_{3-\mathrm{x}}$ composition which we have studied before, indicate changes to the cation distribution along the distance away from the indent (Fig 9 b-c). The results are 
very much similar to previously reported changes to the cation distribution upon fracture with an indented flaw. Further studies are underway to completely characterize the flaw prior to exposure.

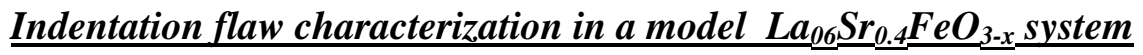

In parallel to the studies on the $\mathrm{La}_{0.2} \mathrm{Sr}_{0.8} \mathrm{Fe}_{0.8} \mathrm{Cr}_{0.2} \mathrm{O}_{3-\mathrm{x}}$ system, indents were characterized in the composition listed in table 1 . The indents were later exposed to air at $1000^{\circ} \mathrm{C}$ to study the interaction of the cracks with the environment. The interaction of a crack with the microstructure in a $\mathrm{La}_{06} \mathrm{Sr}_{0.4} \mathrm{FeO}_{3-\mathrm{x}}$ is shown in figure 10 .

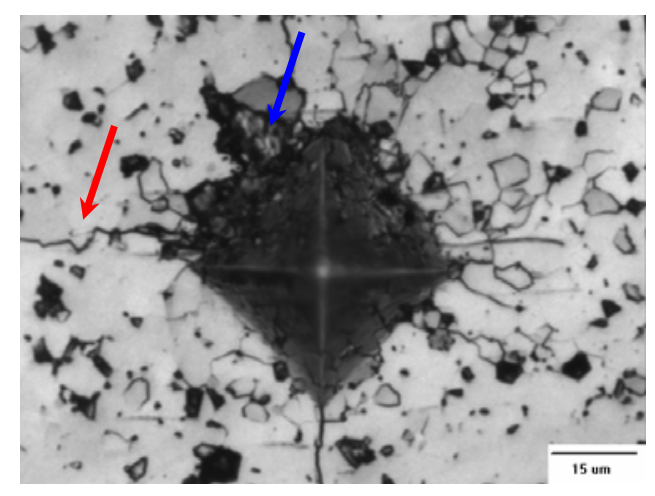

Before exposure

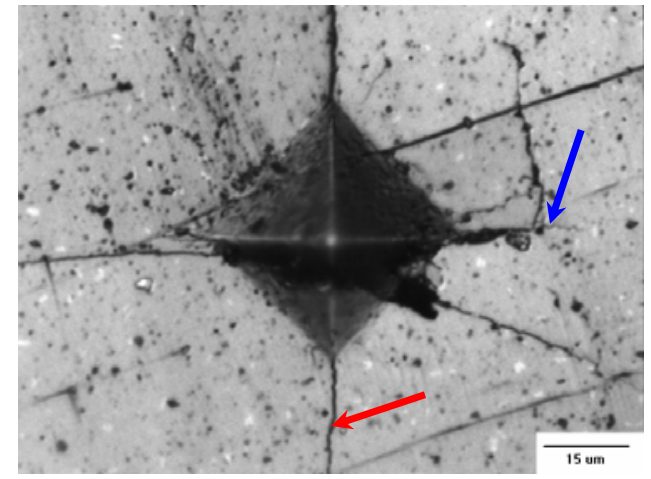

Before exposure

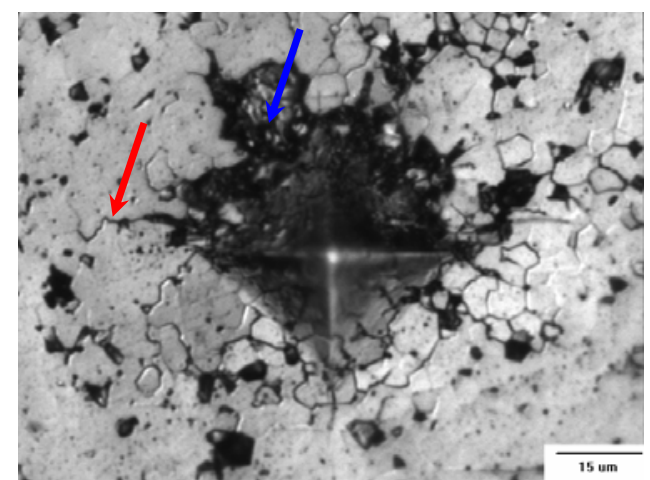

After exposure Air, $1000^{\circ} \mathrm{C}$

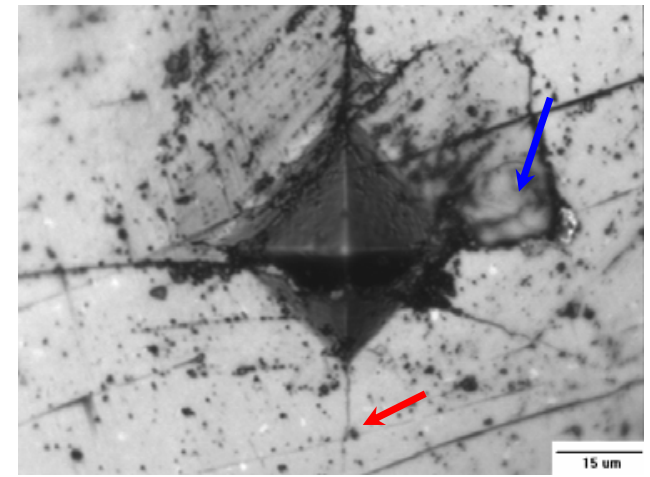

After exposure Air, $1000^{\circ} \mathrm{C}$

Figure 11: An indented flaw exposed to air at $1000^{\circ} \mathrm{C}$ in the $\mathrm{La}_{06} \mathrm{Sr}_{0.4} \mathrm{FeO}_{3-\mathrm{x}}$ system. The crack tip shows healing (in red) upon exposure as also contributing to more damage (in blue)

Upon exposure to air at $1000^{\circ} \mathrm{C}$, the crack in the indented flaws $(10 \mathrm{~N})$ shows healing (highlighted in red) and also increased damage accumulation (highlighted in blue). The reason for the change in mechanism will be analyzed by cross sectioning the indent and characterizing for stress and cation 
distribution. Similar studies in other compositions and environment $\left(\mathrm{N}_{2}\right.$ and $\mathrm{CO} / \mathrm{CO}_{2}$ and $\left.\mathrm{H}_{2}\right)$ will be started and be part of later reports.

\section{Strength Degradation and slow crack growth studies:}

In the last Bi-annual review meeting at Missourri Rolla, it was discussed to begin slow crack growth studies on $\mathrm{La}_{0.2} \mathrm{Sr}_{0.8} \mathrm{Fe}_{0.8} \mathrm{Cr}_{0.2} \mathrm{O}_{3-\mathrm{x}}$ composition. Accordingly, samples were provided by Praxair (Figure 10). The samples were of ASTM standard B which needs reconfiguring of the experimental set up. This will be done shortly and the results reported in the next quarterly report

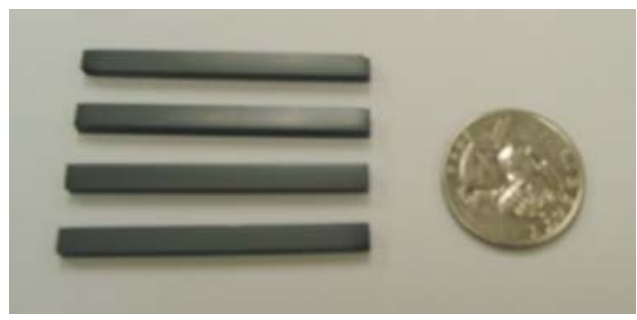

Figure 12: $\quad$ ASTM standard type B samples of $\mathrm{La}_{0.2} \mathrm{Sr}_{0.8} \mathrm{Fe}_{0.8} \mathrm{Cr}_{0.2} \mathrm{O}_{3-\mathrm{x}}$ composition provided by Praxair to study strength degradation with environment.

\section{CONCLUSIONS}

The progress of the task on mechanical properties in chemical environment is on several fronts: a) fundamental understanding and b) studies for the industrial applications. The studies are aimed at generating important parameters for developing a comprehensive model in reliability estimates for the membranes. 


\title{
Task 3: $\quad$ Preparation and Characterization of Dense Ceramic oxygen Permeable Membranes
}

\author{
X.-D Zhou' ${ }^{1}$, Q. Cai ${ }^{2}$, J. Yang1, W. B. Yelon ${ }^{1}$, W. J. James ${ }^{1}$ and H. U. Anderson ${ }^{1}$ \\ 1. Materials Research Center, University of Missouri-Rolla, Rolla, MO 65401 \\ 2. Department of Physics, University of Missouri-Columbia, Columbia, MO 65211
}

Search for the new generation of the oxygen transport membrane materials and the cathode used in intermediate temperature (IT) solid oxide fuel cells (SOFCs) is of great importance in order to increase the energy efficiency and improve the national energy security ${ }^{1,2}$. One technique to improve the materials properties is to tailor its microstructure, for example its porosity, torosity, composite connectivity etc; the other technique is to design the cathode to be mixed ionic and electronic conductor (MIECs) ${ }^{3}$. Neutron diffraction is a powerful tool to characterize these new cathode oxides because it resolves not only the crystal structure, but also the magnetic properties and the oxygen vacancy concentration ${ }^{4-6}$. Compared to $\mathrm{x}$-ray diffraction, neutron diffraction possess couple of significant advantages, including: (1) The sensitivity of neutron scattering to light atoms such as oxygen is far greater than of x-ray scattering because the coherent scattering of neutrons is only determined by the nucleus and independent upon the number of electrons and (2) Neutron has a magnetic moment can probe the magnetic structures and excitations through a strong interaction. Most of the perovskite type oxides $\left(\mathrm{ABO}_{3}\right)$ used as the OTM or the cathodes are magnetic oxides because of the unpaired electron(s) of $\mathrm{B}$ site ions, such as $\mathrm{Mn}^{3+}, \mathrm{Fe}^{3+}$ and $\mathrm{Co}^{3+}$. Moreover, Fe local chemistry, particularly valence state and bonding between $\mathrm{Fe}$ and $\mathrm{O}$, is of great importance in that it is directly related to the electronic conductivity, reaction between oxygen and the ferrites. Mössbauer spectroscopy is a sensitive technique for the studied in terms of the chemical bonding, valence state, and magnetic properties of Fe containing systems (Ferrites). The isomer shift of Mössbauer spectra provides unequivocal information of the valence state of Fe.

\section{EXPERIMENTAL}

The modified Pechini method was used to synthesize nanocrystalline particles, which were calcined at various temperatures to prepare powders. For Neutron Diffraction (ND) studies, samples were contained in $3 \mathrm{~mm} \mathrm{~V}$ metal cells and data were collected at $1.4785 \AA$ over a range of $5^{\circ}-105^{\circ}$ (20). Rietveld refinement was carried out using the FULLPROF code, in which the magnetic 
ordering was taken into account because of the sensitivity of neutron diffraction to the magnetic ordering of the $\mathrm{Fe}$ atoms. Mössbauer spectra were measured using a source of ${ }^{57} \mathrm{Co}$ in $\mathrm{Rh}$ matrix with a conventional constant accelerated driver. Standard $\alpha$ - Fe was used to calibrate the spectrometer with the isomer shift relative to $\alpha-\mathrm{Fe}$ at $300 \mathrm{~K}$.

\section{Results and Discuss}

\subsection{Typical neutron diffraction pattern and refinement}

Figure 1 illustrates typical room temperature neutron diffraction patterns of $\mathrm{La}_{0.60} \mathrm{Sr}_{0.40} \mathrm{FeO}_{3-\delta}$ (L6SF) quenched from $1500^{\circ} \mathrm{C}$. The inserted figure is on the sample without quenching. The most obvious difference between the two patterns is a much stronger low angle $\left(\sim 19^{\circ}\right)$ peak in Fig. 1, which is contributed by the magnetic interaction only. In order to achieve detailed information about magnetic moment, magnetic and crystal structure, refinement of the neutron diffraction data was carried out using the FULLPROF program. Previous studies showed that the refinement using the $\mathrm{R} \overline{3} \mathrm{c}$ space group could resolve oxygen content. Very recently, it was found that refinement in the trigonal space group $\mathrm{P}-3 \mathrm{C} 1$ on the same data resulted in an improvement of the fit parameters, which in turn gave more realistic oxygen occupancy. For example, an observed peak at about $41^{\circ}$ for the specimen quenched from $1000^{\circ} \mathrm{C}$ is not modeled in $\mathrm{R} \overline{3} \mathrm{c}$, which can be fitted in $\mathrm{P}-3 \mathrm{C} 1$. The magnetic moment and unit cell volume, however, are found to be essentially independent of the choice of crystallographic model. Because there is a high correlation between the occupancies of each of these sites, unconstrained refinements of the occupancy of each site leads to a small overpopulation of one site, reasonable total occupancy, and a large statistical uncertainty on the total occupancy.

\subsection{Crystallographic Structure}

From all the quenched samples, similar patterns as shown in Fig. 1 were observed, showing them to be single phase. Crystal structure at various quenching temperature is shown in Figure 2, in which $\mathrm{a}^{*}$ represents $\mathrm{a} / \sqrt{2}$ and $\mathrm{c}^{*}$ is $\mathrm{c} / 2 \sqrt{3}$. The symmetry of L6SF quenched from 600 to $1200^{\circ} \mathrm{C}$ at room temperature remains as rhombohedral (space group $\mathrm{R} \overline{3} \mathrm{c}$ ). The rhombohedral splitting of the peaks becomes not obvious for the specimens quenched from $\mathrm{T}>1200^{\circ} \mathrm{C}$, which indicates a significant lattice distortion from the rhombohedral cell to the cubic cell. This distortion becomes small $\left(\sim 0.06^{\circ}\right)$ in samples quenched from $\mathrm{T}>1300^{\circ} \mathrm{C}$. The unit cell volume increases monotonically as the quenching temperature increases, by a total of $3.8 \AA^{3}$ from $355.72 \AA^{3}$ (without quenching) to 
$359.52 \AA^{3}$ (quenched from $1500^{\circ} \mathrm{C}$ ). The uncertainty in this determination is estimated to be about $0.04 \AA^{3}$ suggesting that increasing of unit cell volume $(\sim 1.1 \%)$ was resulted from increasing of oxygen vacancy concentration and ionic radius of Fe ion, which in turn can be a good method for the determination of vacancy concentration.

\subsection{Local Chemistry of Fe and Magnetic moments}

\subsubsection{Magnetic interaction}

$\mathrm{La}_{0.60} \mathrm{Sr}_{0.40} \mathrm{FeO}_{3-\delta}$ exhibits an antiferromagnetic - paramagnetic transition, hence the magnetic moments on the two Fe sites are constrained to be equal, and the room temperature moment was found to increase from $1.3 \mu_{\mathrm{B}}$ for the sample without quenching to $3.4 \mu_{\mathrm{B}}$ for the $1500^{\circ} \mathrm{C}$ specimen. The reason for increasing magnetic moment mainly is due to the distribution of $3+$ and $4+$ ions.

Since the $\mathrm{Fe}^{4+}$ ions have small or zero moments, the exchange interactions in this system are expected to be dominated by the $\mathrm{Fe}^{3+}-\mathrm{Fe}^{3+}$ interactions. These will obviously increase markedly as the $\mathrm{Fe}^{3+}$ concentration increases with increasing oxygen vacancies. The magnetization of $\mathrm{La}_{0.60} \mathrm{Sr}_{0.40} \mathrm{FeO}_{3-\delta}$ as a function of temperature follows the Brillouin curve: saturated at low temperature and decreasing slowly up to about $70 \%$ of $\mathrm{T}_{\mathrm{N}}$ and more rapidly as $\mathrm{T}_{\mathrm{N}}$ is approached. Thus, for unquenched L6SF, where the Fe-O-Fe angle is small, and the $\mathrm{Fe}^{4+}$ concentration large, $\mathrm{T}_{\mathrm{N}}$ is low and the room temperature moment is small. $\mathrm{T}_{\mathrm{N}}$ increases to $\sim 410^{\circ} \mathrm{C}$ for the specimen quenched from $1500^{\circ} \mathrm{C}$, therefore the room temperature moment is little affected by the change in superexchange and $\mathrm{T}_{\mathrm{N}}$. However, the same effect that leads to the variable saturation moment (the ratio of low moment $\mathrm{Fe}^{4+}$ and high moment $\mathrm{Fe}^{3+}$ ) will dominate the room temperature moment when the ordering temperature is high. Since the Fe atoms are antiferromagnetically ordered, this effect cannot be observed using bulk magnetic measurements, but can easily be seen with the neutron diffraction measurements. When the composition reaches $\mathrm{La}_{0.6} \mathrm{Sr}_{0.4} \mathrm{FeO}_{2.8}$, it is expected that the system will reach its maximum average moment. Beyond this point $\mathrm{Fe}^{2+}$ is expected to appear, also with a smaller moment than $\mathrm{Fe}^{3+}$, and the room temperature moment would then be expected to decrease. Indeed this trend was seen in the $\mathrm{CO} / \mathrm{CO}_{2}$ reduced samples.

\subsubsection{Fe valence state}

The relative ratio of $\mathrm{Fe}^{3+}$ and $\mathrm{Fe}^{4+}$ ions for $\mathrm{La}_{0.60} \mathrm{Sr}_{0.40} \mathrm{FeO}_{3-\delta}$ without quenching obtained from relative areas of the Mössbauer spectra is 64:36, indicating a nearly zero oxygen vacancy in these compounds. This ratio changes to $70: 30$ for the specimen quenched from $800^{\circ} \mathrm{C}$, showing an increase of oxygen vacancy concentration. As the quench temperature becomes higher than $900^{\circ} \mathrm{C}$, the $\mathrm{Fe}^{4+}$ spectrum disappears $\left(\mathrm{Fe}^{4+}\right.$ normally is non-magnetic with a single line) and the magnetic 
sextets become dominant. The spectra of the specimens quenched from $\mathrm{T}>1200^{\circ} \mathrm{C}$ are particularly sharp, which represents an increase in the Fe magnetic ordering temperature and suggests a structural transformation in the sample. It is found that the valence state of Fe changes from 3.36 to 3.04, suggesting that the $\mathrm{Fe}$ valence states change from a mixture of $\mathrm{Fe}^{3+}$ and $\mathrm{Fe}^{4+}$ to about $96 \% \mathrm{Fe}^{3+}$ as quenched at $1500^{\circ} \mathrm{C}$. The change in the valence state of Fe results in an increase in both the hyperfine field and magnetic moment for the quenched samples. The oxygen content $\delta$ changes from 0.02 to 0.18 per formula after quenching at $1500^{\circ} \mathrm{C}$. The oxygen contents $\delta$ obtained from Mössbauer spectra are again consistent with those obtained from the neutron diffraction refinements.

Since the isomer shift provides direct information about the electron density at the nucleus, we have attempted to derive information about the valence states of $\mathrm{Fe}$ ions in these compounds. By using the average IS ${ }^{7}$ of the quenched $\mathrm{La}_{0.60} \mathrm{Sr}_{0.40} \mathrm{FeO}_{3-\delta}$, the average valence states of the $\mathrm{Fe}$ is shown in Figure 3. It is found that the valence state of Fe changes from 3.36 to 3.04, suggesting that the $\mathrm{Fe}$ valence states change from a mixture of $\mathrm{Fe}^{3+}$ and $\mathrm{Fe}^{4+}$ to about $96 \% \mathrm{Fe}^{3+}$ as quenched at $1500^{\circ} \mathrm{C}$. The change in the valence state of Fe results in an increase in both the hyperfine field and magnetic moment for the quenched samples. The quadrupole splitting (QS) of the Fe ions decreases as the quench temperatures increasing $\left(\mathrm{T}>1200^{\circ} \mathrm{C}\right)$, which indicates a crystal symmetry transformation from distorted-cubic to cubic, and shows nearly no splitting when the cubic perovskite structure is attained.

\section{Conclusions:}

Neutron diffraction and Mössbauer spectroscopy were used to characterize the $\mathrm{La}_{0.60} \mathrm{Sr}_{0.40} \mathrm{FeO}_{3-\delta}$, a OTM and cathode candidate for the intermediate temperature solid oxide fuel cells. Crystal structure, magnetic moment and Fe valence state were studied on the specimens quenched from $700^{\circ} \mathrm{C}$ to $1500^{\circ} \mathrm{C}$. It was found that a lower symmetry trigonal space group P-3C1

gives improved fits to the data including the matching of a peak not fitted in the $\mathrm{R} \overline{3} \mathrm{c}$ symmetry. A significant lattice distortion from rhombohedral to cubic was observed in the sample quenched from $\mathrm{T}>1200^{\circ} \mathrm{C}$. Average Fe valence state and saturated magnetic moment are $\sim 3.04$ and $3.7 \mu \mathrm{B}$ respectively for $\mathrm{La}_{0.60} \mathrm{Sr}_{0.40} \mathrm{FeO}_{3-\delta}$ quenched from $1500^{\circ} \mathrm{C}$, indicating that $\delta$ is $\sim 0.2$. In the specimen without quenching, average Fe valence state and low temperature magnetic moment are $\sim 3.4$ and $2.4 \mu \mathrm{B}$ and the fraction of $\mathrm{Fe}^{3+}$ is $\sim 60 \%$, therefore $\delta$ is $\sim 0$, which indicates a full oxygen occupancy. 


\title{
TASK 4: Assessment of Microstructure of the Membrane Materials to Evaluate the Effects of vacancy-Impurity Association, defect Clusters, and Vacancy Dopant Association on the Membrane Performance and Stability
}

\author{
Professor Nigel Browning, University of Illinois Chicago Circle
}

\section{EXPERIMENTAL}

The key to obtaining detailed information on the structure, composition and bonding at interfaces and defects is linked to the ability of the STEM to form a small electron probe. Figure 13 shows a schematic of the detector arrangement in the STEM demonstrating that all the signals of interest for materials characterization can be acquired simultaneously, relative to the probe position on the surface of the sample. The starting point for the analysis is the Z-contrast image, which is formed by collecting the high-angle scattering on an annular detector (Figure 1). Detecting the scattered intensity at these high-angles and integrating over a large angular range effectively averages coherence effects between neighboring atomic columns in the specimen. Thermal vibrations reduce the coherence between atoms in the same column to residual correlations between near neighbors, a second order effect. This allows each atom to be considered as an independent scatterer. Scattering factors may be replaced by cross sections, and these approach a $Z^{2}$ dependence on atomic number. This cross section effectively forms an object function that is strongly peaked at the atom sites, so for very thin specimens where there is no dynamical diffraction, the detected intensity consists of a convolution of this object function with the probe intensity profile (Figure 13). The small width of the object function $(\sim 0.02 \mathrm{~nm})$ means that the spatial resolution is limited only by the probe size of the microscope. For a crystalline material in a zone-axis orientation, where the atomic spacing is greater than the probe size, the atomic columns are illuminated sequentially as the probe is scanned over the specimen. An atomic resolution compositional map is thus generated, in which the intensity depends on the average atomic number of the atoms in the columns.

This result also holds true for thicker specimens. In this case, the experimental parameters cause dynamical diffraction effects to be manifested as a columnar channeling effect, thus maintaining the thin specimen description of the image as a simple convolution of the probe intensity profile and an object function, strongly peaked at the atom sites. The phase problem associated with the interpretation of conventional high-resolution TEM images is therefore eliminated. In thin 
specimens, the dominant contribution to the intensity of a column is always its composition. However, due to the higher absorption of the heavy strings the contrast does decrease with increasing specimen thickness and in very thick crystals there is no longer a high resolution image. The effect of changing focus is also intuitively understandable as the focus control alters the probe intensity profile on the surface of the specimen. For defocus less than the optimum Scherzer condition, the probe broadens causing the individual columns not to be resolved. For higher defocus values the probe narrows with the formation of more intense tails, causing sharper image features but compositional averaging over several columns. The optimum focus condition therefore represents a compromise between high resolution (narrow probe profile) and the desire for a highly local image (no tails to the probe). This focus condition also corresponds to the optimum probe for microanalysis.

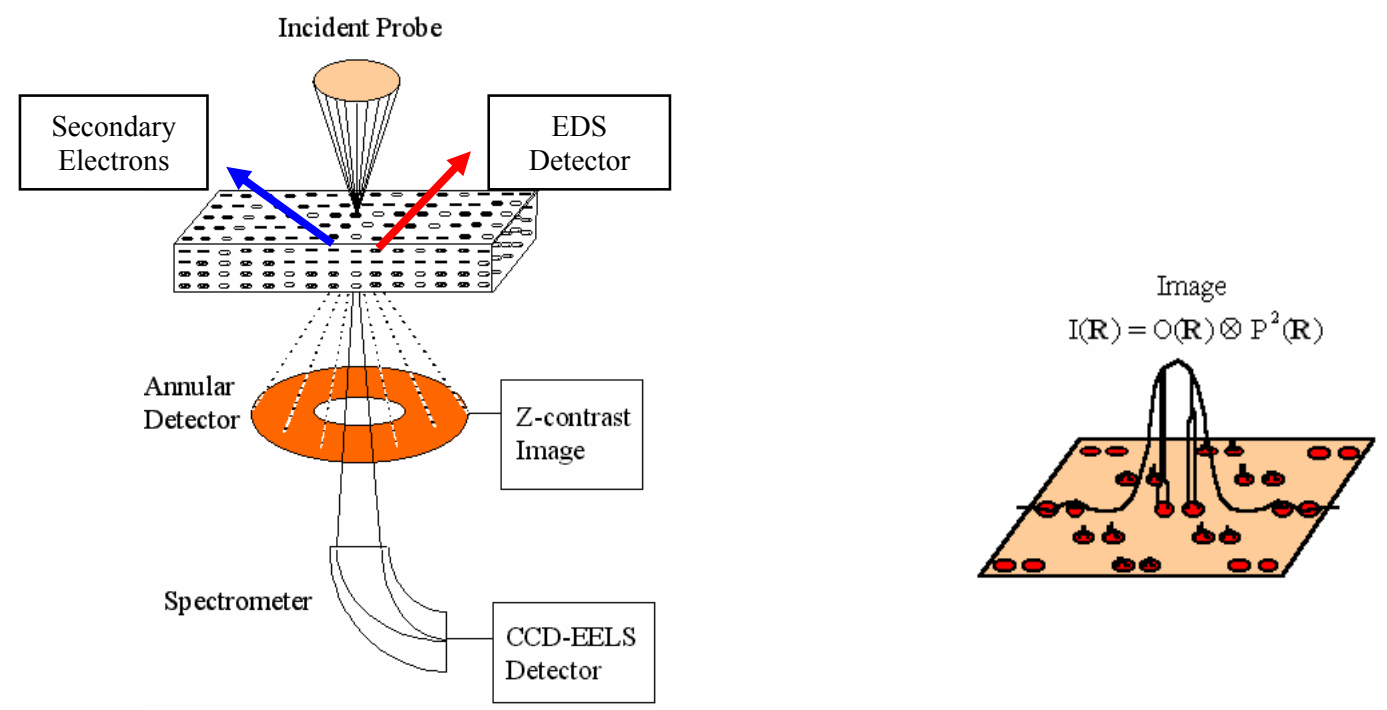

Figure 13: (a) Schematic of the STEM. (b) The Z-contrast image and energy loss spectrum can be interpreted as a simple convolution of the experimental probe and the object function. With lower spatial resolution, the EDS spectrum can also be interpreted in this manner.

As can be seen from Figure 13, the annular detector used for Z-contrast imaging does not interfere with the low-angle scattering used for EELS. This means that the Z-contrast image can be used to position the electron probe over a particular structural feature for acquisition of a spectrum. The physical principle behind EELS relates to the interaction of the fast electron with the sample to cause either collective excitations of electrons in the conduction band, or discrete transitions between 
atomic energy levels, e. g. $1 \mathrm{~s} 2 \mathrm{p}$ transitions. The ability to observe discrete atomic transitions allows compositional analysis to be performed by EELS (the transitions occur at characteristic energy losses for a given element). Furthermore, the transitions to unoccupied states above the Fermi level allows the degree of hybridization between atomic orbitals to be determined, i.e. information on local electronic structure (bonding) changes can be ascertained. To be able to correlate these features of the spectrum precisely with a structural feature of interest, it is essential that the spectrum have the same atomic resolution as the Z-contrast image. In order to achieve this atomic resolution, the range over which a fast electron can cause an excitation event must be less than the inter-atomic spacing. Hydrogenic models show that for the majority of edges accessible by conventional energy-loss spectrometers. $\mathrm{E}<2 \mathrm{keV}$ ) the object functions are localized within $0.1 \mathrm{~nm}$ of the atom cores. Hence, like the Z-contrast image, we have an object function localized at the atom cores and an experimental probe of atomic dimensions. For crystalline materials in zone-axis orientations, providing we maintain a large collection angle, the description of the spectrum (Figure 1) in terms of a convolution of the probe with an object function is valid.

In the results presented here from the current quarter's research, the analytical techniques have been extended to include energy dispersive X-ray spectroscopy and secondary electron imaging. These techniques are standard analytical methods for the transmission electron microscope (TEM), STEM and the scanning electron microscope (SEM) and will not be discussed further here.

\section{RESULTS}

Figure 14 shows images obtained from a representative area of the membrane material. One of the advantages of the JEOL 2500SE used to obtain these images is that it permits a secondary electron image of the sample surface to be obtained. By comparing this image to the bright field (thicker regions are darker) and dark field (thicker regions are brighter) we can identify several key features in the sample. The most obvious features of the sample are the precipitates that can be clearly observed in all the images. The changes in contrast indicate that these precipitates may be thinner than the matrix in which they are embedded or be of a different composition. The contrast in the three images gives some indication of a thickness change, but the composition cannot be verified without obtaining EDS spectra from the sample. 

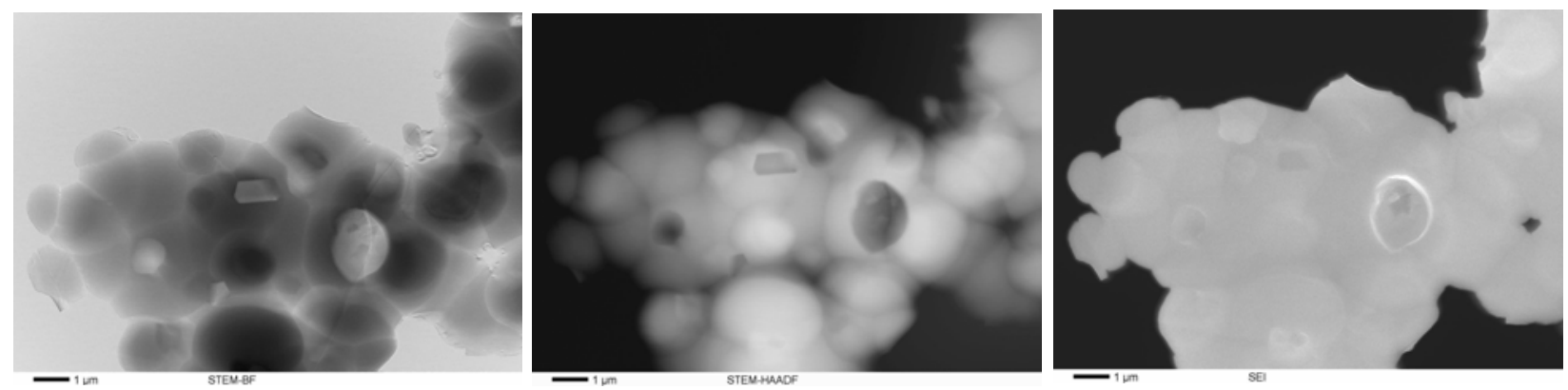

Figure 14: (a) Bright field (b) Z-contrast and (c) secondary electron images of a representative area of the membrane material.

Figure 15 shows the results of the X-ray maps obtained from the area of sample shown in figure 14. Here, a full EDS spectrum is acquired at each pixel in the scan across the sample and then this complete scan is used to provide an intensity map of a given peak. In the case of the sample here, the $\mathrm{Fe}, \mathrm{Cr}, \mathrm{La}, \mathrm{Sr}, \mathrm{O}$ and $\mathrm{Mg}$ peaks were found to have a major presence in the spectra, and so these peaks were used to form the images. From these scans, some of the features from the images can be understood. The large irregular patches in the bright field and dark field images are shown to be thinner areas. In these cases, it is likely that the grains that occupied these spaces fell out during processing. Other features in these spectral images show that there are regular facetted secondary phases existing. In both cases, these phases appear to be composed of $\mathrm{FeCrMgO}$. It is not immediately clear where the $\mathrm{Mg}$ comes from, but this will be addressed in future work. Another interesting results of these images, is that all the spectral maps shown the same intensity changes at the grain boundaries, indicating that there is no significant enrichment of the grain boundaries by any particular element. 

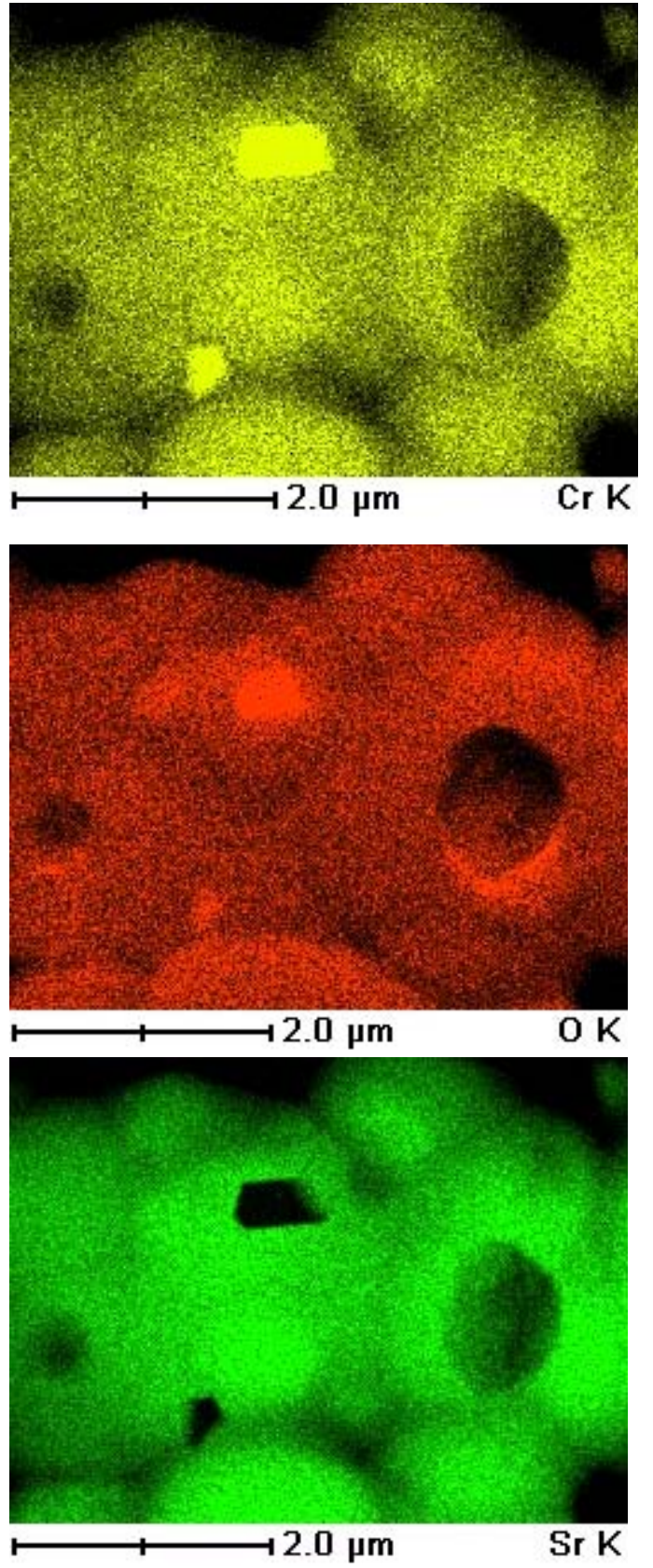
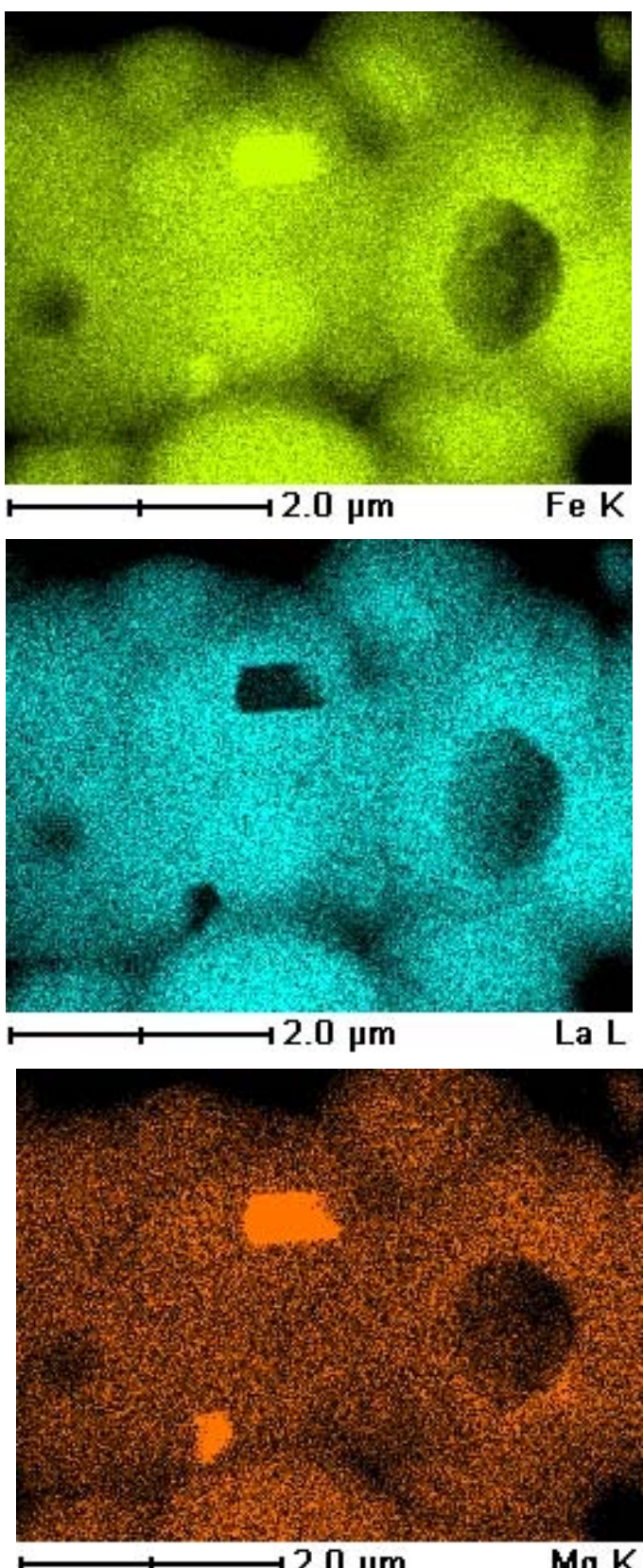

$\mathrm{Mg} \mathrm{K}$

Figure 15: Elemental profiles of the area shown in figure 14.

The lack of segregants at the grain boundaries has been investigated further using the atomic resolution imaging and spectroscopy techniques. The initial findings suggest that the major effect that occurs at the grain boundaries is an increase in the number of oxygen vacancies. However, at the time of writing this report, the spectra were still being analyzed. The results of this analysis will be presented in the next report. 


\section{CONCLUSIONS}

The sample shown above is only one of a series of nine samples. The plan for the next three months is to continue to analyze the spectroscopic information from the current sample and then broaden the analysis to the other samples. Completion of the set of analyses is expected to take up to 6 months. 


\title{
Task 5: Measurement of Surface Activation/Reaction rates in lon Transport Membranes using Isotope Tracer and Transient Kinetic Techniques.
}

\author{
Prof. Alan Jacobson, University of Houston/University of Toronto
}

\section{EXPERIMENTAL}

\section{Conductivity and Thermodynamic Studies}

We have continued to investigate the thermodynamic properties (stability and phase separation behavior) and total conductivity of prototype membrane materials. The data are needed together with the kinetic information to develop a complete model for the membrane transport. We have completed measurements of the oxygen non-stoichiometry on $\mathrm{SrFeO}_{3-\mathrm{x}}, \mathrm{La}_{0.5} \mathrm{Sr}_{0.5} \mathrm{FeO}_{3-\mathrm{x}}$, and $\mathrm{La}_{0.2} \mathrm{Sr}_{0.8} \mathrm{Fe}_{0.8} \mathrm{Cr}_{0.2} \mathrm{O}_{3-\mathrm{x}}$. During this quarter we have started to characterize a new composition provided by Praxair, $\mathrm{La}_{0.2} \mathrm{Sr}_{0.8} \mathrm{Fe}_{0.55} \mathrm{Ti}_{0.45} \mathrm{O}_{3-\mathrm{x}}$. The sample was provided in the form of a powder.

X-ray diffraction and microprobe analysis

The $\mathrm{La}_{0.2} \mathrm{Sr}_{0.8} \mathrm{Fe}_{0.55} \mathrm{Ti}_{0.45} \mathrm{O}_{3-x}$ powder was calcined at a series of temperatures $\left(1200{ }^{\circ} \mathrm{C}, 1250{ }^{\circ} \mathrm{C}\right.$ and $1300{ }^{\circ} \mathrm{C}$ in air to investigate phase purity and densification behavior. The $\mathrm{X}$-ray data are shown in Figure 16. The sample is apparently single phase after heating at $1220 \mathrm{C}$ though some line broadening is apparent. At $1300{ }^{\circ} \mathrm{C}$ the lines become sharper and the pattern can be completely indexed with a tetragonal unit cell with lattice parameters $a=5.506(9) \AA$ and $c=7.787(9) \AA$. The density measured by the Archimedes method was $96 \%$ of the theoretical value after annealing the sample for $10 \mathrm{~h}$ at $1300{ }^{\circ} \mathrm{C}$ or at $1350{ }^{\circ} \mathrm{C}$ for $10 \mathrm{~h}$. The sample densified at $1350{ }^{\circ} \mathrm{C}$ was more brittle than that at $1300{ }^{\circ} \mathrm{C}$ sample and the latter was used for conductivity measurements. 


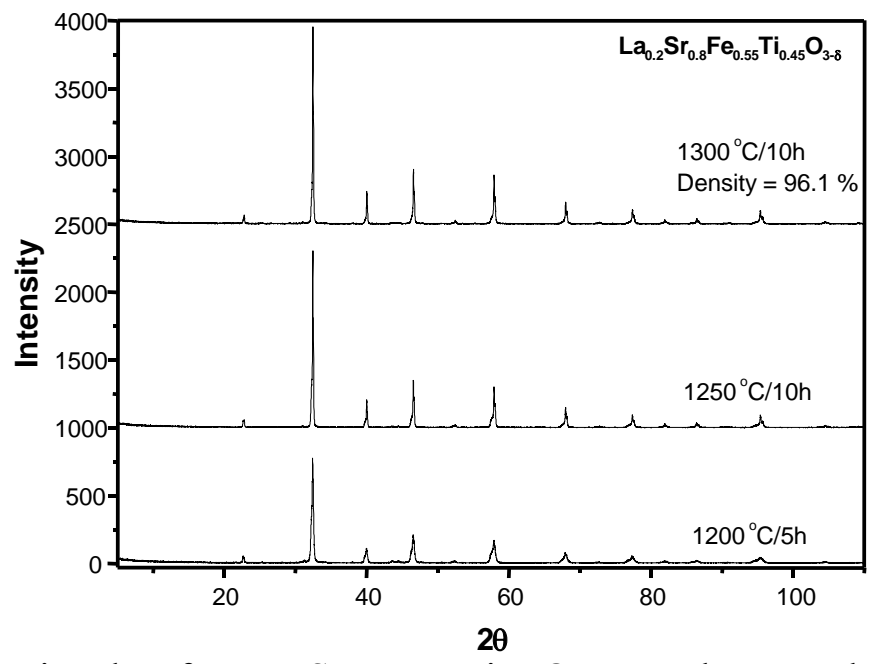

Figure 16. X- ray diffraction data for $\mathrm{La}_{0.2} \mathrm{Sr}_{0.8} \mathrm{Fe}_{0.55} \mathrm{Ti}_{0.45} \mathrm{O}_{3-\mathrm{x}}$ samples annealed at different temperatures.
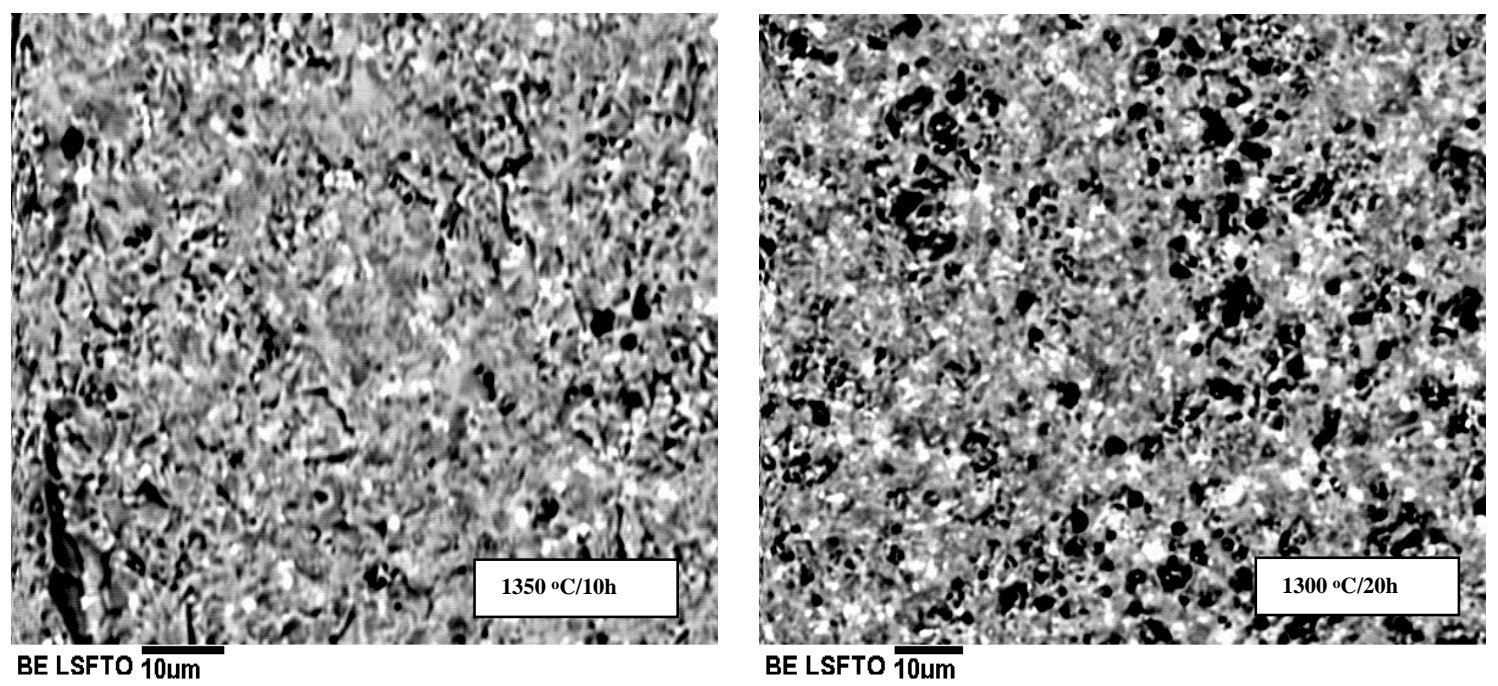

Figure 17. Back-scattered electron images of $\mathrm{La}_{0.2} \mathrm{Sr}_{0.8} \mathrm{Fe}_{0.55} \mathrm{Ti}_{0.45} \mathrm{O}_{3-\mathrm{x}}$

Samples were mounted and polished for electron microprobe analysis using a JEOL JXA-8600 Electron Microprobe. Backscattered electron images taken in the microprobe are shown in Figure 17. Elemental compositions were determined with the probe placed at different spots on the sample and the composition ratios determined from the average data to be $\mathrm{La}: \mathrm{Sr}=0.2: 0.87$ and $\mathrm{Fe}: \mathrm{Ti}=0.55$ : 0.43 in reasonable agreement with the nominal composition. Some variation in composition was observed in most part due to the roughness of the sample surfaces. We will go back with fresh samples to improve the data. Some bright spots were also observed which were found to be strontium rich, may explain the higher than expected Sr content. 
A rectangular bar with dimensions $0.67 \times 0.29 \times 0.20 \mathrm{~cm}$ was cut from the sample

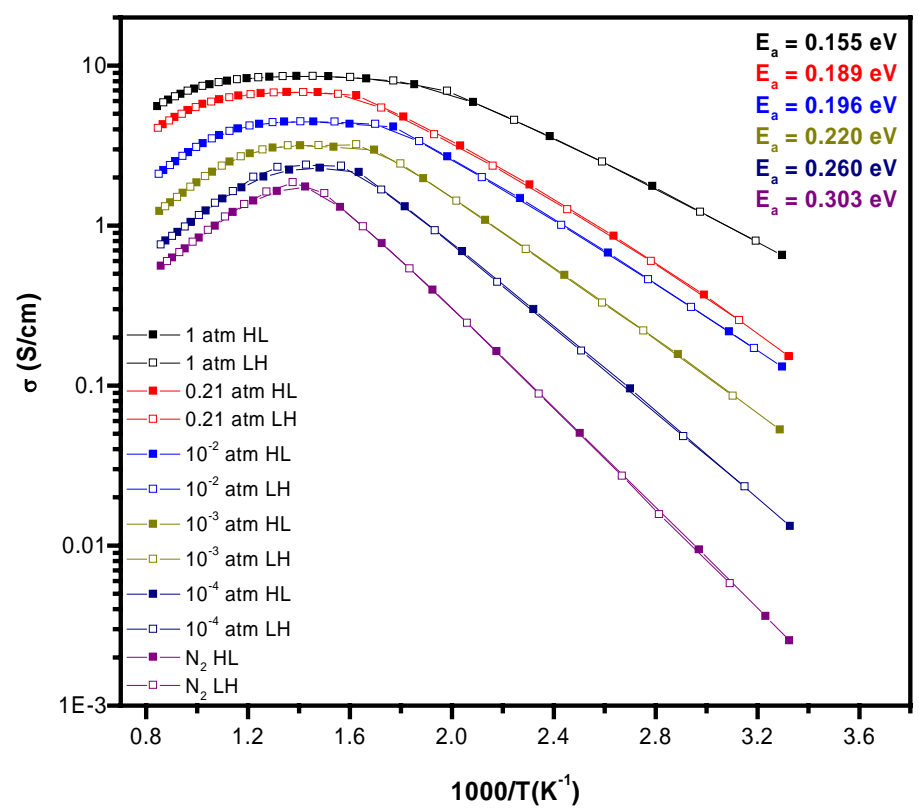

Figure 18. DC conductivity data for $\mathrm{La}_{0.2} \mathrm{Sr}_{0.8} \mathrm{Fe}_{0.55} \mathrm{Ti}_{0.45} \mathrm{O}_{3-\mathrm{x}}$ in different gas atmospheres as a function of reciprocal temperature

That was sintered at $1300^{\circ} \mathrm{C}$. Conductivity measurements were made as a function of temperature in different gas atmospheres by the four-probe dc method. Gold wires were used as electrodes and measurements were made on both heating and cooling to ensure that equilibrium had been attained. The results are shown in Figure 18. The results are typical for perovskite materials. The conductivity shows Arrhenius behavior at temperatures lower than about $300{ }^{\circ} \mathrm{C}$. The activation energy increases with decreasing oxygen partial pressure as the contribution from ionic conductivity to the total conductivity increases. The maximum conductivity observed in $\mathrm{pO}_{2}=1$ atm is $\sim 10 \mathrm{~S} \mathrm{~cm}^{-1}$. Above $300{ }^{\circ} \mathrm{C}$, the conductivity falls as the oxygen stoichiometry increases because of the relationship $\left[S r^{\prime}\right]=\left[b^{\bullet}\right]+2\left[V^{\bullet \bullet}\right]$. At the higher oxygen pressures, a plateau is observed in the conductivity before the steep fall off. The origin of this plateau is not yet known but may be a consequence of the way in which the stoichiometry depends on temperature or it may be a kinetic effect.

A rectangular bar with dimensions $0.76 \times 0.25 \times 0.23 \mathrm{~cm}$ was cut from the sample sintered at $1300{ }^{\circ} \mathrm{C}$. Measurements were made in a sealed electrochemical cell as a function of oxygen partial pressure at temperatures from $750{ }^{\circ} \mathrm{C}$ to $1000{ }^{\circ} \mathrm{C}$ down to $10^{-17}$ atm for the lowest temperature. The measurements were made using and ac technique at a single frequency and the phase angle monitored to confirm the absence of any polarization effects. Measurements were made on both decreasing and increasing $\mathrm{pO}_{2}$ and the results are shown in Figure 4. 


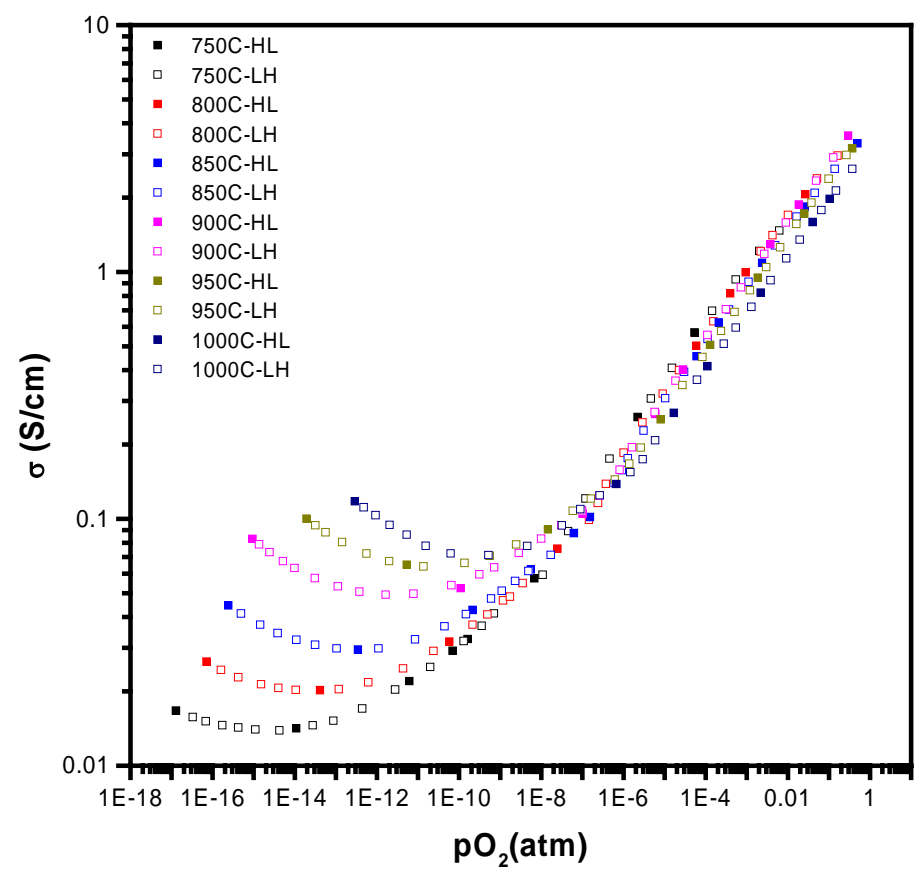

Figure 19. Conductivity measurements for $\mathrm{La}_{0.2} \mathrm{Sr}_{0.8} \mathrm{Fe}_{0.55} \mathrm{Ti}_{0.45} \mathrm{O}_{3-\mathrm{x}}$ as a function of $\mathrm{pO}_{2}$ at different temperatures. Open and closed symbols represent data taken on increasing and decreasing $\mathrm{pO}_{2}$

The data are typical for perovskite oxides. The conductivity initially $\mathrm{p}$ type at high oxygen partial pressure decreases as $\mathrm{pO}_{2}$. The slope of the linear region in a $\log -\log$ plot is $\sim 1 / 4$ as expected. Little temperature variation is seen in this region presumably because the decrease in hole conductivity associated with oxygen loss is offset by an increase in the ionic conductivity. As the $\mathrm{pO}_{2}$ is further decreased, the conductivity goes through a minimum and then becomes $\mathrm{n}$ type with a $\mathrm{pO}_{2}{ }^{-1 / 4}$ dependence. In general, the system is well behaved with little evidence for problems in attaining equilibrium that we have found in the other iron systems that we have studied. The $\mathrm{p}$ to $\mathrm{n}$ transition is well defined at all temperatures.

The $\mathrm{pO}_{2}$ dependence of the conductivity data for $\mathrm{La}_{0.2} \mathrm{Sr}_{0.8} \mathrm{Fe}_{0.55} \mathrm{Ti}_{0.45} \mathrm{O}_{3-\mathrm{x}}$ were further analyzed using a simple model that expresses the total conductivity as the sum of the ionic conductivity and the $\mathrm{p}$ and $\mathrm{n}$ type contributions according to: $\sigma_{\mathrm{T}}=\mathrm{A}+\mathrm{B} \times \mathrm{pO}_{2}{ }^{1 / 4}+\mathrm{C} \times \mathrm{pO}_{2}{ }^{-1 / 4}$. This simple model fits the data well (see Table 1) though it does not take proper account of the behavior in the $p$ type region where changes in the stoichiometry effect the ionic conductivity (by changing the vacancy concentration) in addition changing the hole contribution. The two off setting effects lead to an apparent near zero activation energy (see Figure 20). 
Table 3. Results from the model fit to the $\mathrm{pO}_{2}$ dependence of the total conductivity data

\begin{tabular}{llll}
$\mathrm{La}_{0.2} \mathrm{Sr}_{0.8} \mathrm{Fe}_{0.55} \mathrm{Ti}_{0.45} \mathrm{O}_{3-\mathrm{x}}$ & $\mathrm{A}$ & $\mathrm{B}$ & $\mathrm{C}$ \\
\hline $750{ }^{\circ} \mathrm{C}$ & 0.0110 & 5.844 & $3.57 \times 10^{-7}$ \\
$800{ }^{\circ} \mathrm{C}$ & 0.0157 & 5.090 & $9.15 \times 10^{-7}$ \\
$850{ }^{\circ} \mathrm{C}$ & 0.0222 & 4.591 & $2.70 \times 10^{-6}$ \\
$900{ }^{\circ} \mathrm{C}$ & 0.0362 & 4.428 & $8.00 \times 10^{-6}$ \\
$950{ }^{\circ} \mathrm{C}$ & 0.0415 & 4.183 & $2.00 \times 10^{-5}$ \\
$1000{ }^{\circ} \mathrm{C}$ & 0.0423 & 3.495 & $6.00 \times 10^{-5}$ \\
\hline
\end{tabular}

Nevertheless, reasonable values for the ionic conductivity are derived $\sim 0.03 \mathrm{Scm}^{-1}$ with an apparent activation energy of $0.66 \mathrm{eV}$.

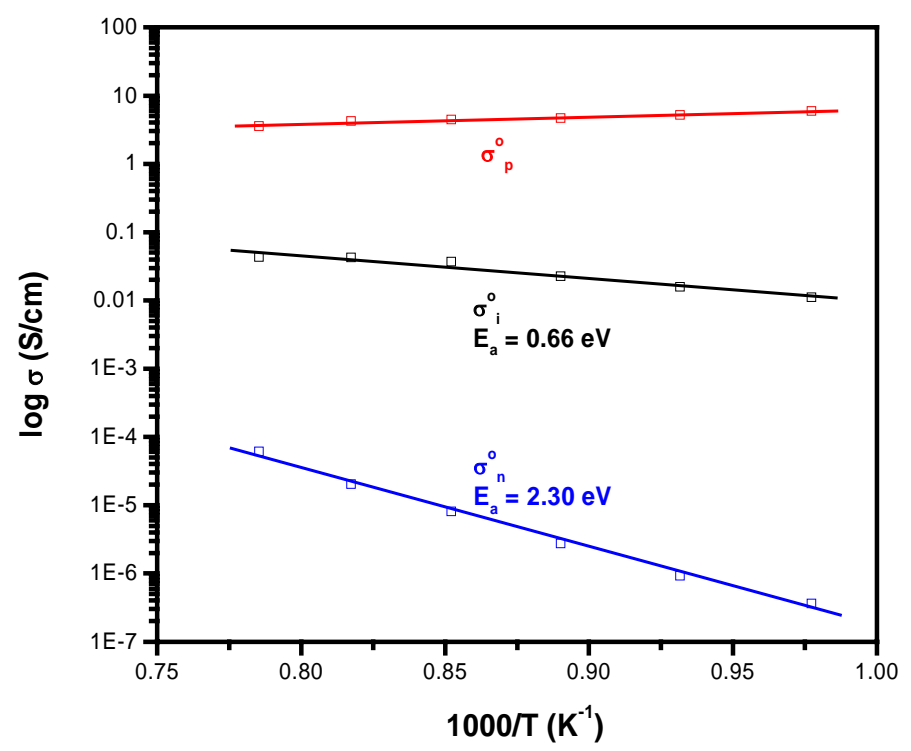

Figure 20. The individual contributions to the total conductivity of $\mathrm{La}_{0.2} \mathrm{Sr}_{0.8} \mathrm{Fe}_{0.55} \mathrm{Ti}_{0.45} \mathrm{O}_{3-\mathrm{x}}$.

\section{Plans for next quarter.}

We will extend studies of the $\mathrm{La}_{0.2} \mathrm{Sr}_{0.8} \mathrm{Fe}_{0.55} \mathrm{Ti}_{0.45} \mathrm{O}_{3-\mathrm{x}}$ sample to include measurements of the oxygen partial pressure dependence of the oxygen stoichiometry and electrical conductivity relaxation studies to determine the diffusion and the surface exchange coefficients. We will prepare dense tubular ceramics for use in the membrane reactor at UT. 


\section{University of Toronto}

\section{Isotope Transient Studies of Oxygen Permeation Through a Dense $\mathrm{La}_{0.6} \mathrm{Sr}_{0.4} \mathrm{Co}_{0.2} \mathrm{Fe}_{0.8} \mathrm{O}_{3-\delta}$ Membrane}

We have continued to study isotope transients $\left({ }^{16} \mathrm{O}_{2^{-}}{ }^{18} \mathrm{O}_{2}\right)$. The apparatus and procedure has been

previously described - briefly the isotopic transient is initiated by introducing an ${ }^{18} \mathrm{O}_{2}$ isotope pulse to the "air" $\left(20 \% \mathrm{O}_{2}\right.$ : Ar $)$ side of the membrane while maintaining a constant $\mathrm{pO}_{2}$. The isotopic composition of the oxygen permeate is analyzed on the delivery side, swept with helium, to reveal the residence time distribution of oxygen in the membrane under steady state transport. The resulting isotope transient allows the unambiguous separation of surface and bulk resistances to oxygen permeation under steady state conditions, a separation not possible by permeation measurements alone.

\section{Summary of experimental progress}

The following experiments were performed on a second tubular membrane $(6 \mathrm{~mm}$ o.d., $1 \mathrm{~mm}$ wall thickness) of $\mathrm{La}_{0.6} \mathrm{Sr}_{0.4} \mathrm{Co}_{0.2} \mathrm{Fe}_{0.8} \mathrm{O}_{3-\delta}$.

(1) The flux dependence on oxygen partial pressure both the air side and on the deliver side were seen to be in fair agreement with the previous membrane.

(2) Isotope transients were performed at $750^{\circ} \mathrm{C}, 800^{\circ} \mathrm{C}$ and $850^{\circ} \mathrm{C}$.

(3) The isotope transient measurements were extended to simultaneously record the transient on the air side.

(4) The oxygen activity profile through the membrane was calculated from the obtained surface and bulk kinetics.

(5) Isotope transients were performed at different oxygen pressure gradients, by varying the He sweep rate and the oxygen pressure on the air side.

(6) The membrane was quenched during the final isotope transient and will be sectioned for isotope profiling.

The transient data obtained on this sample are currently being analyzed.

Finally, we have begun investigations on a membrane of $\mathrm{La}_{0.2} \mathrm{Sr}_{0.8} \mathrm{Cr}_{0.2} \mathrm{Fe}_{0.8} \mathrm{O}_{3-\delta}$. 
Oxygen permeation measurements. The sample was heated at a ramping rate of ca. $2{ }^{\circ} \mathrm{C} / \mathrm{min}$ to 750 C. The stamdard flow rates of air and the sweeping gas He were basically $20 \mathrm{ml} / \mathrm{min}$ in our experiments. The composition of sweeping gas was analyzed by a SRI 8610C Gas Chromatograph with a molecular-sieve column. A Helium Ionization Detector (HID) was used to measure the oxygen and nitrogen content since HID is with a high sensitivity. The dependence of the flux on the oxygen partial pressure on the air side is shown in Figure 21.

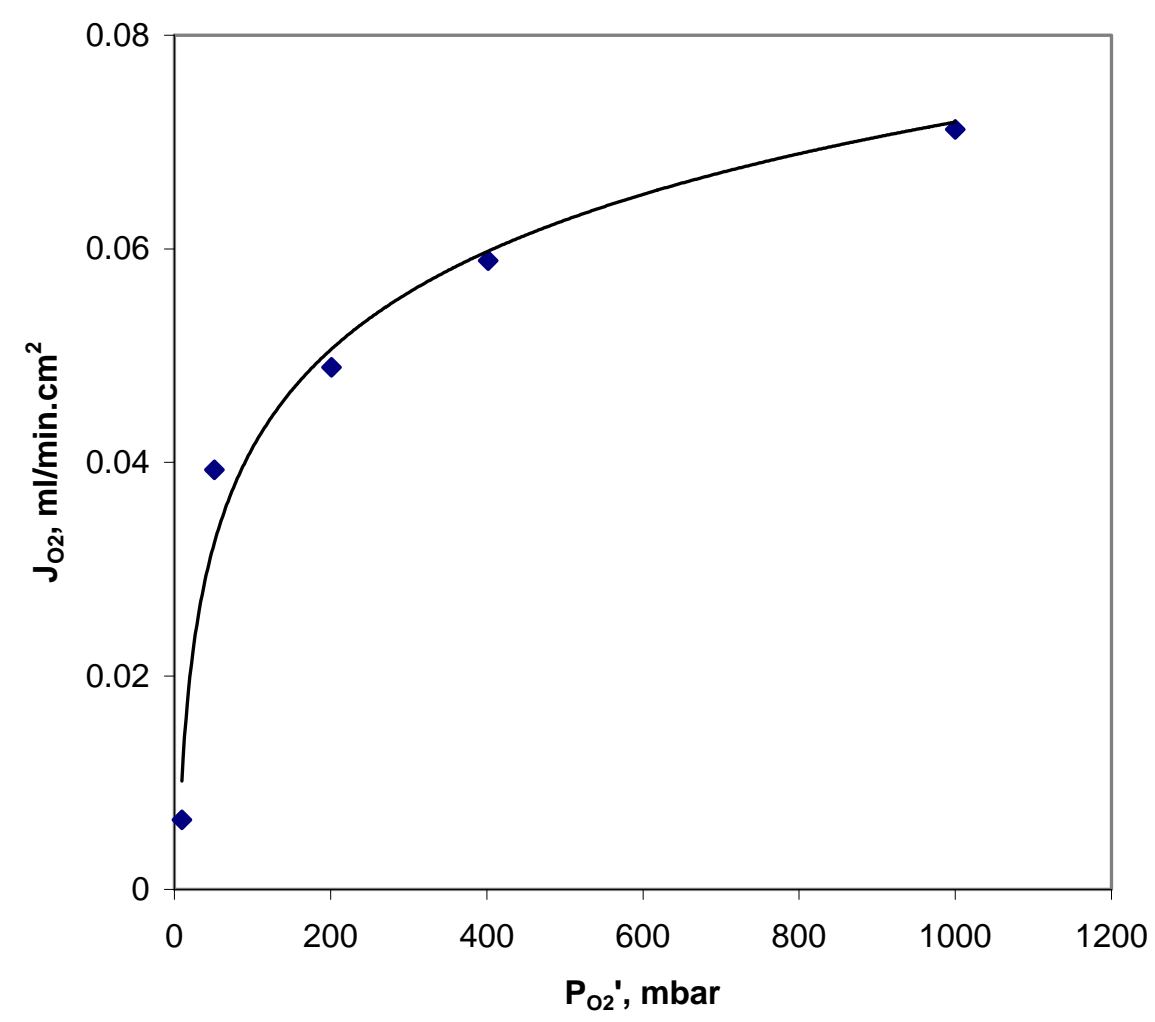

Figure 21. Oxygen flux as function of $\mathrm{P}_{\mathrm{O} 2}$. He sweep $=20 \mathrm{sccm}$.

Figure 22 shows the flux variation with the He sweep rate on the delivery side. An 8-fold variation in PO2" was produced in these experiments. 


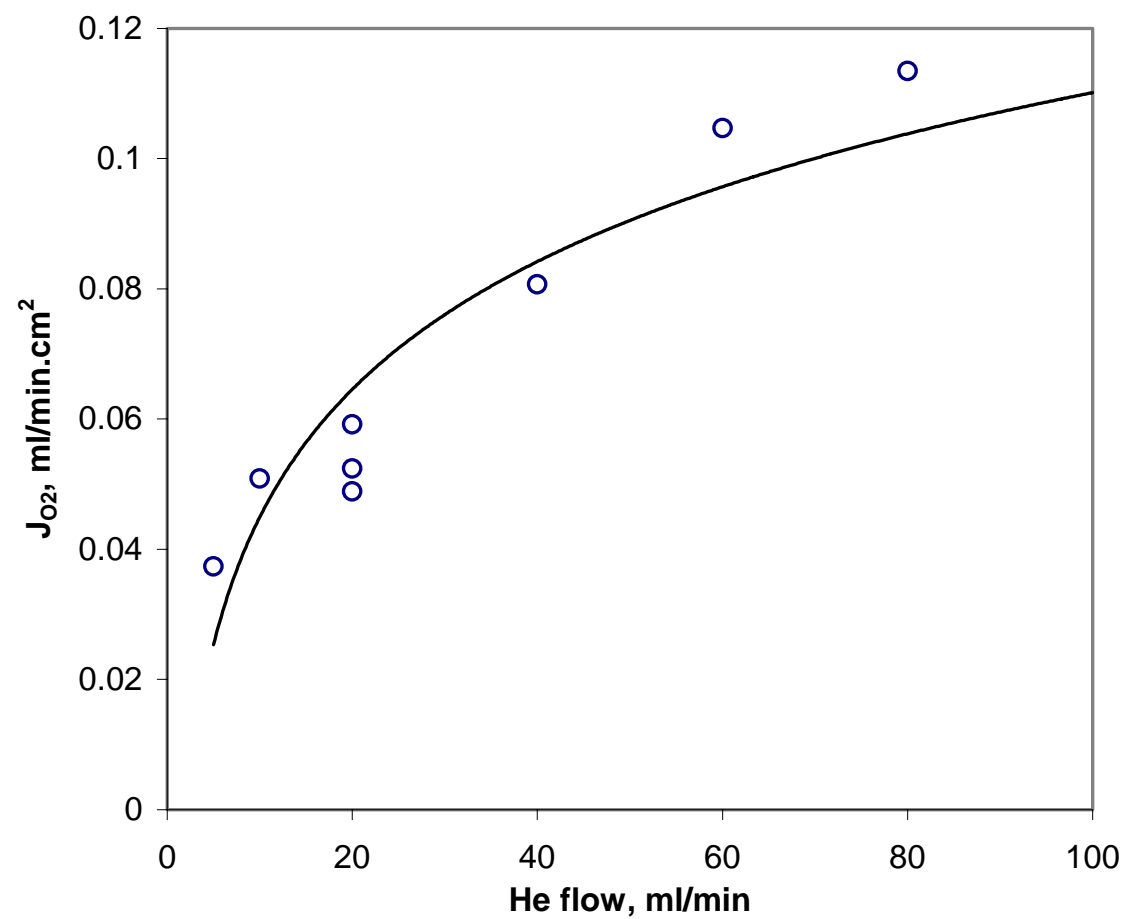

Figure 22. The effect of sweeping He flow rate on $\mathrm{O}_{2}$ flux for LSCF-6428 at $800{ }^{\circ} \mathrm{C}$

The following equation, which was reported by $\mathrm{Xu}$ and Thomson ${ }^{10}$, is used to fit the data and shown by the solid line in the Figure.

$J_{O 2}=\frac{\frac{k_{r}}{k_{f}}\left(\frac{1}{P^{\prime \prime}{ }_{O 2}^{0.5}}-\frac{1}{P_{O 2}^{\prime}{ }^{0.5}}\right)}{\frac{1}{k_{f} P_{O 2}^{\prime}{ }^{0.5}}+\frac{2 L}{D_{v}}+\frac{1}{k_{f} P_{O 2}{ }^{0.5}}}$

The leak rates in this membrane were at first much lower than in the previous membrane, but as time progressed the leak rate increased.

\section{Isotope transients:}

Isotope transients were performed at all three temperatures $\left(750{ }^{\circ} \mathrm{C}, 800{ }^{\circ} \mathrm{C}\right.$ and $\left.850{ }^{\circ} \mathrm{C}\right)$ and at two He sweep rates. The fits derived from the simple model transients, though adequate to obtain transport parameters, were not as good as those on the previous membrane - a fact which we attribute to some possible heterogeneity in the tube. 


\section{Transients on the air side.}

The reversibility of the surface exchange on the air side indicates the gradient in oxygen potential across the air side surface. The shape of the isotope transient and the amount of delivered isotope is sensitive to this, and therefore values of the reversibility can be derived from the measured transient on the sweep side. The dependences of the shape and quantities of the delivered isotope on surface reversibility are subtle, however and uncertainties in the validity of the simple 1-D model can render this an uncertain process.

To counteract this, we began measuring the isotope transient on the air side in the time immediately following the isotope pulse. Figure 23 shows such a measurement along with fits to the data for various values of the reversibility (expressed as $\mathrm{k}_{\mathrm{r}} / \mathrm{k}_{\mathrm{f}}$ ).

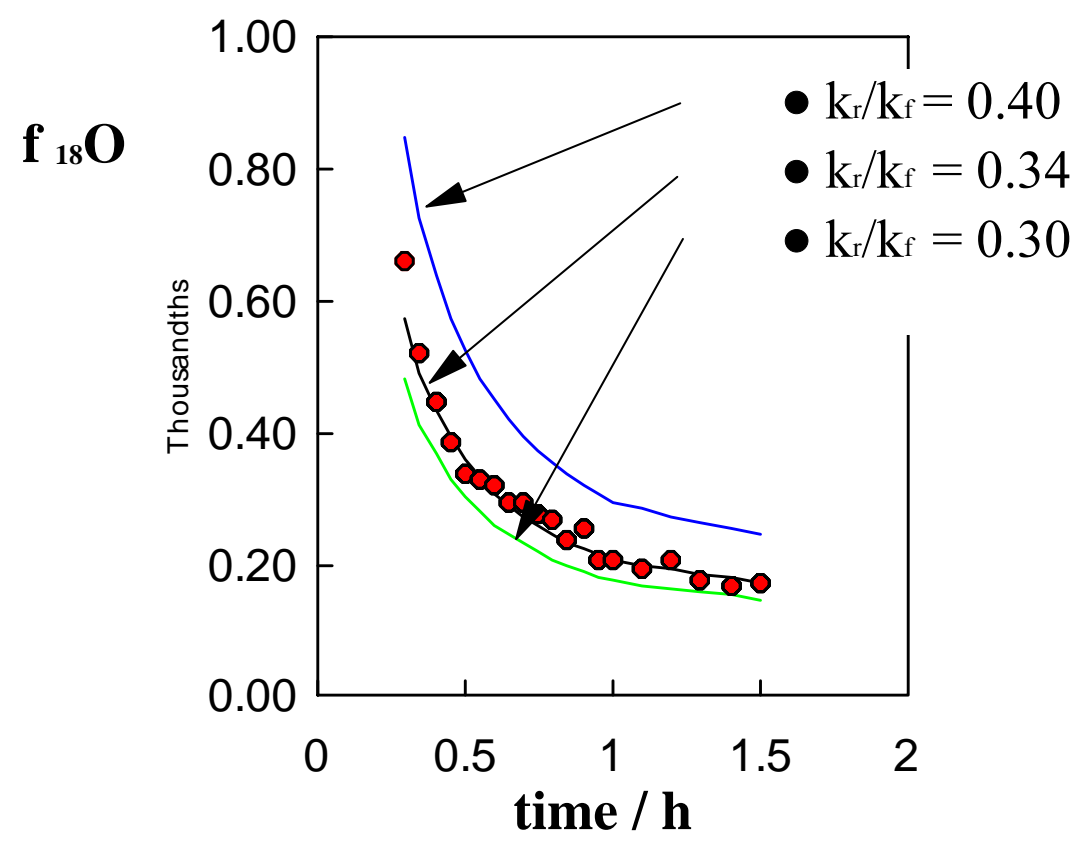

Figure 23: Isotope transient on the air side of the membrane at $800^{\circ} \mathrm{C}$. The indicated values are of the ratio of the reverse to forward surface exchange coefficients.

The sensitivity of the fit to the value of the rate ratio is apparent. In effect, the total amount of isotope infused during the pulse can be measured by adding the isotope which exits from both sides of the 
membrane and provides a firm value of $\mathrm{k}_{\mathrm{f}}$. The split between the two sides depends on how rapidly the isotope moves away from the air-side surface and is thus coupled to both the oxygen flux and the oxygen diffusivity in the sample.

Oxygen activity profile calculations:

The oxygen potential gradient across the air-side surface is related to the reversibility of the surface exchange. Perfect reversibility signifies equilibrium and therefore no oxygen potential drop. Obtaining quantitative values for this requires knowledge of the rate law for the surface activation process and therefore requires experiments at several oxygen partial pressures. We are currently analyzing our data to extract this behavior.

Similarly, the oxygen potential drop across the bulk of the membrane related to the diffusive flux compared to the net flux. This relationship, assuming constant properties in the material is given by a simple version of the Wagner equation.

$$
\ln \left(p^{\prime} \mathrm{O} 2, \text { surface } / \mathrm{p}^{\prime \prime} \mathrm{O} 2 \text {, surface }\right)=2 \Phi_{\mathrm{O}} \mathrm{L} /\left(\mathrm{C}_{\mathrm{O}} \mathrm{D}_{\mathrm{O}}\right)
$$

The gradient profile for one of the experiments is shown in Figure 9.

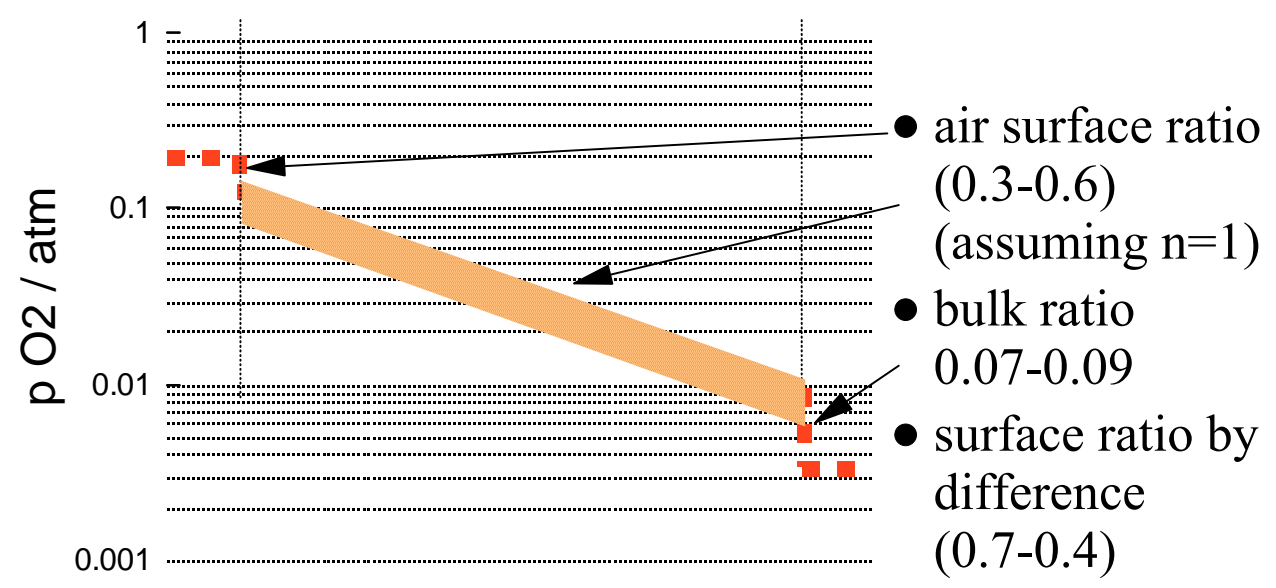

Figure 24: Oxygen potential gradient across LSCFO-6428 membrane at $800^{\circ} \mathrm{C}$. 
The surface exchange coefficient is assumed to depend on the first power of the oxygen partial pressure. If the activation is half order in oxygen pressure, then the oxygen potential drop at the air side surface would be twice a large. We are analyzing the rest of the data in this manner.

\section{Transients at differing gradients:}

The surface activation coefficient should agree with IEDP measurements if the surface exchange is reversible. If a strong gradient exists at the surface, however, then the forward rate will be much larger than reverse rate and the surface will experience a different oxygen potential from the gas phase. The table below shows the results of our first analysis of the surface exchange under two different oxygen fluxes. Two different He sweep rates produce two different oxygen gradients across the entire membrane. This gradient is shared among the surfaces and the bulk. The increase in the oxygen gradient results in an apparent increase in the forward surface coefficient.

Table 4: Surface rates at two different flux conditions on LSCFO-6428 at $800^{\circ} \mathrm{C}$

\begin{tabular}{lllll}
\hline He sweep & $\mathrm{O}_{2}$ flux & $\mathrm{p}^{\prime \prime} \mathrm{O}_{2}$ & $\mathrm{D}_{\mathrm{O}}$ & $\mathrm{k}_{\mathrm{f}}$ \\
\hline \multicolumn{5}{c}{ (He sweep side) } \\
Sccm & $\mathrm{sccm} \mathrm{cm}^{-2}$ & $\mathrm{~atm}$ & $10^{-8} \mathrm{~cm}^{2} \mathrm{~s}^{-1}$ & $10^{-6} \mathrm{~cm} \mathrm{~s}^{-1}$ \\
20 & 0.12 & 0.0074 & 6.4 & $3.3(0.5)$ \\
60 & 0.17 & 0.0038 & 6.9 & $4.9(0.6)$ \\
\hline
\end{tabular}

We are analyzing other transients in the recent set to see if consistent trends in surface activation rates in non-equilibrium conditions can be obtained in these experiments. 


\section{Quenching of membrane during transient:}

The LSCFO-6428 membrane was quenched from reaction conditions during an isotope transient. This tube will be sectioned and the isotope profile will be measured. This will test the predictions of our model, and also reveal any heterogeneities in the tube which would complicate the analysis of the transients. Model predictions for one condition, using the transport parameters fit from previous transients are shown below. The sample was quenched at 6 hours into the transient. A crack opened up during the rapid cooling but the profiles should be unaffected.

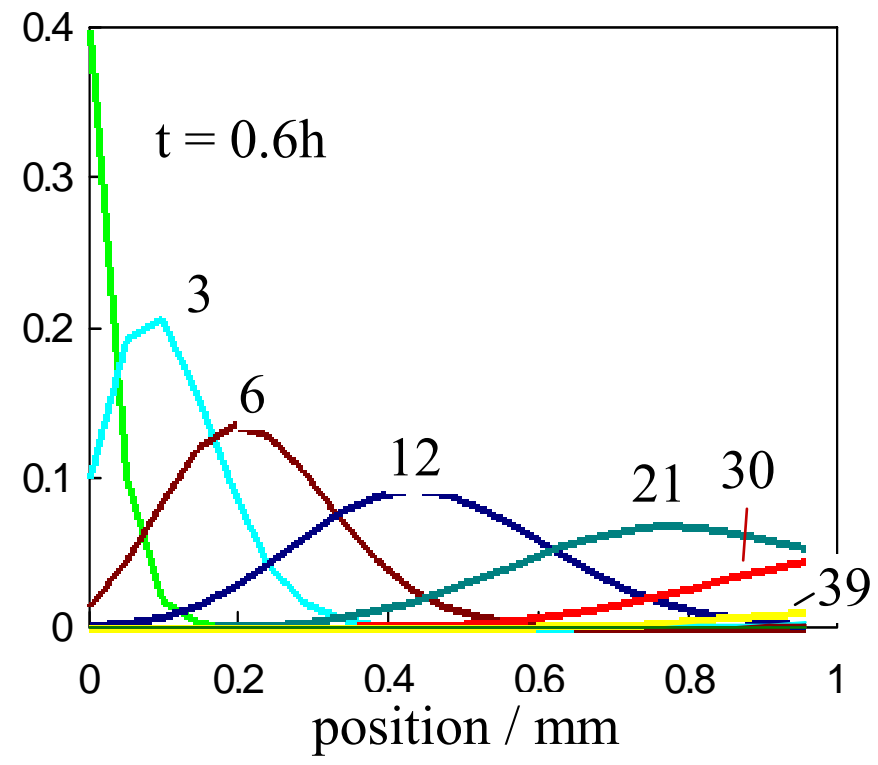

Figure 25: Isotope profile in solid at various times after isotope pulse introduction.

\section{Plans for next quarter.}

We will finish the analyses on the LSCF-6428 membrane data, including the profile in the quenched sample. The new $\mathrm{La}_{0.2} \mathrm{Sr}_{0.8} \mathrm{Fe}_{0.8} \mathrm{Cr}_{0.2} \mathrm{O}_{3-\mathrm{x}}$ membrane will be examined cursorily for oxygen permeation, including isotope transients, followed by a series of experiments with oxygen on one side and $\mathrm{CO}_{2}: \mathrm{CO}$ on the other. These first high gradient experiments will require extending the model. New $\mathrm{La}_{0.2} \mathrm{Sr}_{0.8} \mathrm{Fe}_{0.55} \mathrm{Ti}_{0.45} \mathrm{O}_{3-\mathrm{x}}$ samples will be first examined by IEDP experiments. Membrane experiments will then follow. 


\section{CONCLUSIONS}

A better model for the thermochemical interactions between zirconia layers and $\mathrm{Ti}$ thin films allows a better estimation of the processing times necessary to obtain a stable interface in perovskite/metal applications where zirconia-based diffusion barriers are used to decrease the interaction between the TLPB alloy and the substrate itself. Furthermore, the model develop in this work may eventually be applied to describe the detrimental liquid metal/perovskite interactions that prevent the creation of reliable perovskite/metal interfaces without the use of protective diffusion barriers.

The progress of the task on mechanical properties in chemical environment is on several fronts: a) fundamental understanding and b) studies for the industrial applications. The studies are aimed at generating important parameters for developing a comprehensive model in reliability estimates for the membranes. Initial Transmission Electron Microscopy results are available on only one of a series of nine samples from the previous studies on mechanical test studies. The plan for the next three months is to continue to analyze the spectroscopic information from the current sample and then broaden the analysis to the other samples. Completion of the set of analyses is expected to take up to 6 months.

Neutron diffraction and Mössbauer spectroscopy were used to characterize the $\mathrm{La}_{0.60} \mathrm{Sr}_{0.40} \mathrm{FeO}_{3-}$, a OTM and cathode candidate for the intermediate temperature solid oxide fuel cells. Crystal structure, magnetic moment and Fe valence state were studied on the specimens quenched from $700^{\circ} \mathrm{C}$ to $1500^{\circ} \mathrm{C}$. It was found that a lower symmetry trigonal space group P-3C1

gives improved fits to the data including the matching of a peak not fitted in the $\mathrm{R} \overline{3} \mathrm{c}$ symmetry. A significant lattice distortion from rhombohedral to cubic was observed in the sample quenched from $\mathrm{T}>1200^{\circ} \mathrm{C}$. Average Fe valence state and saturated magnetic moment are $\sim 3.04$ and $3.7 \mathrm{~B}$ respectively for $\mathrm{La}_{0.60} \mathrm{Sr}_{0.40} \mathrm{FeO}_{3-\delta}$ quenched from $1500^{\circ} \mathrm{C}$, indicating that $\delta$ is $\sim 0.2$. In the specimen without quenching, average Fe valence state and low temperature magnetic moment are $\sim 3.4$ and 2.4 $\mathrm{B}$ and the fraction of $\mathrm{Fe}^{3+}$ is $\sim 60 \%$, therefore $\delta$ is $\sim 0$, which indicates a full oxygen occupancy.

Studies will be extended on the $\mathrm{La}_{0.2} \mathrm{Sr}_{0.8} \mathrm{Fe}_{0.55} \mathrm{Ti}_{0.45} \mathrm{O}_{3-\mathrm{x}}$ sample to include measurements of the oxygen partial pressure dependence of the oxygen stoichiometry and electrical conductivity relaxation studies to determine the diffusion and the surface exchange coefficients. Dense tubular ceramics will be prepared for use in the membrane reactor at UT. Also, analyses will be finished on the LSCF-6428 membrane data, including the profile in the quenched sample. The new $\mathrm{La}_{0.2} \mathrm{Sr}_{0.8} \mathrm{Fe}_{0.8} \mathrm{Cr}_{0.2} \mathrm{O}_{3-\mathrm{x}}$ membrane will be examined cursorily for oxygen permeation, including 
isotope transients, followed by a series of experiments with oxygen on one side and $\mathrm{CO}_{2}: \mathrm{CO}$ on the other. These first high gradient experiments will require extending the model. New $\mathrm{La}_{0.2} \mathrm{Sr}_{0.8} \mathrm{Fe}_{0.55} \mathrm{Ti}_{0.45} \mathrm{O}_{3-\mathrm{x}}$ samples will be first examined by IEDP experiments. 


\section{References:}

1. D. A. Berry, W. A. Surdoval and M. C. Williams, 222nd ACS National Meeting, Chicago, IL, United States, (2001).

2. S. P. Simner, J. F. Bonnett, N. L. Canfield, K. D. Meinhardt, V. L. Sprenkle, and J. W. Stevenson, Electrochem. Solid State Lett., 5, A173 (2002).

3. B. C. H. Steele, J. Mater. Sci., 36, 1053 (2001).

4. H. U. Anderson, X.-D. Zhou and F. Dogan, Proceeding of the Electrochem. Soc. 2002, (in press)

5. J. B. Yang, W. B. Yelon, W. J. James, Z. Chu, M. Kornecki, Y. X. Xie, X. D. Zhou, H. U. Anderson, A. G. Joshi and S. K. Malik, Phys. Rev. B, 66, 184415 (2002).

6. D. E. Cox, IEEE Trans. Magn., MAG - 8, 161 (1972).

7. S. E. Dann, D. B. Currie, M. T. Weller, M. F. Thomas, and A. D. Al-Rawwas, J. Solid State Chem., 109, 134 (1994). 
BIBLIOGRAPHY:

N/A 
LISTS OF ACRONYMS AND ABBREVIATIONS:

N/A 